\title{
Deciphering the crime-terror Nexus: an empirical analysis of the structural characteristics of terrorists in Narco-terror networks
}

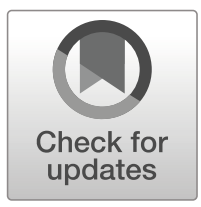

\section{Mustafa Coşar Ünal ${ }^{1}$}

Published online: 24 August 2019

(C) Springer Nature B.V. 2019

\begin{abstract}
By using Social Network Analysis (SNA) technique, this study analyzes the structural characteristics of five PKK related narco-terror networks. It examines the roles and positions occupied by PKK members to uncover the nature of the terrorist nexus itself and analyzes structural characteristics to identify these networks' prioritization between security and efficiency. This study finds that terrorists have key roles in narco-terror networks, i.e., leaders, managers, or drug suppliers. They take powerful and central positions in either controlling central hubs (exerting authority) or bridging separate subgroups (acting as a gateway) constituting the core parts of networks. Further, this study finds that despite terrorists' dominating role and positions in control and coordination of information and resources, narco-terror networks reveal more reliance on efficiency than security. In general, these networks tend to be clustered into dense subgroups that are attached to networks' cores, reflecting relatively denser and centralized structures with short average paths. Yet, networks have core(s) whereby key players act predominantly in these cores rather than on peripheries. Notwithstanding the dominance of terrorist members, narco-terror networks seem to focus more on efficiency, and the terrorist nexus in such networks does not appear to make these networks more security-driven. This study asserts that the nature of activity (i.e., crime for material incentive) determines how offenders behave and how covert networks are structured.
\end{abstract}

Keywords Crime-terror Nexus · Narco-terrorism · Social network analysis · Dark/covert networks

Mustafa Coșar Ünal

cosar.unal@bilkent.edu.tr

1 Department of Political Science and Public Administration, Bilkent Universitesi, Ankara, Turkey 


\section{Introduction}

The linkage between terrorist networks and criminal groups, known as the crime-terror nexus, has been a growing concern on national and international security agendas. This is largely because of terrorist and insurgent groups' increasing participation in criminal activities in order to finance their campaigns as well as criminal gangs' engagement in violent political acts serving to further their criminal influence.

Criminal and terrorist groups have continuously adapted to shifting environments and changing structures in order to sustain and expand their activities. Recently, the "nexus" between these originally distinct entities has deepened, evolved, and become more complex [1-4]. Despite the fact that terrorist and insurgent groups are involved in many criminal activities ranging from petty crimes to human trafficking [4], the most notable one has been illicit drug trafficking [5]. Initially characterized by the Latin American drug cartels and insurgent groups in the 1990s, "narco-terrorism" has been a growing phenomenon in regions linked to Central and Southeast Asia, specifically the narcotics-producing regions of the so-called Golden Crescent and the Golden Triangle [5-7]. Hutchinson and O'malley [2: 1098], Shelley and Picarelli [8: 62-3], and Wang [9: 14] note that drug trafficking is the largest source of income for terrorist and criminal organizations. Many scholars have reported on terrorist groups' drug trafficking activities and identified the associated security risks (e.g., [10-13]).

What is considered more important for policy implications, though, is the nature and characteristics of the "nexus" itself between terrorist organizations and criminal networks $[1,3,14,15]$. Understanding the characteristics of the phenomenon is deemed critical for criminal intelligence and law enforcement units to develop effective countermeasures against it, e.g., identifying key players, structural holes, and disruption points [16-22]. In that, Ballina [23: 122] argues that special attention must be given to the role that narcoterrorism plays in the crime-terror nexus for three main reasons. First, as argued by Asal et al. [24: 112], the nexus between crime and terror is ambiguous, and this ambiguity is most evident in the character of the link between terrorist organizations and illicit drug organizations. Second, as Björnehed [5: 306] reports, illicit drug networks are the most popular referent when the term crime-terror nexus is brought up. That is, illicit drug organizations are driven by material incentives reflecting the managerial and business-like spirit of crime ([23]: 122). This is narco-terrorism's most distinctive nature from ideologically driven terrorist groups [25]. Third, the drug-terror nexus is not definite or standardized due to the different types and scale of drug and terror organizations [5], varying temporality and scale of their linkages, and the different geo-political conditions in which they operate $[1,3,14]$.

Given the aforementioned, this study focuses on the drug-terror nexus in the Turkish context - between Central Asia and Europe - by examining randomly sampled five narco-terror networks that had links to the Kurdistan Workers' Party (Partiya Karkerên Kurdistanê, PKK) - an insurgent group employing guerrilla and terrorism as a method [26]. Turkey, like many other countries, is positioned at a juncture where drug trafficking and terrorism intersect $[1,4,27]$. It is situated on a major drug trafficking path called the "Balkan Route" and is characterized as a transit country between the drug producing countries of Central Asia and the Middle East and destination countries in Europe via the Balkans [27]. Drug networks in Turkey play an important role in transporting heroine and morphine base in Afghanistan to Europe [1, 4]. Illicit drug trade in and outside of 
Turkey has been one of the PKK's financing activities [28] among others, such as fundraising from Kurdish diaspora across the Europe, extortion, and so forth [27].

Although Turkey's aforementioned geopolitical stance and the linkage between drug trafficking and the PKK have been mentioned on many accounts in academia (e.g., [1, $4,27,28]$ ), there has been no empirical study analyzing the nexus between illicit drug trafficking and PKK armed group in Turkey.

In this context, this research questions the PKK nexus in drug trafficking networks in the Turkish context and addresses "how PKK members are positioned and what roles are taken by them in narco-terror networks in Turkey." Related with this, this research also analyzes "whether or not having PKK members, as terrorists/insurgents in these criminal drug networks made these entities more security driven" by questioning the sampled drug-terror (PKK) networks' structural characteristics vis-à-vis securityefficiency trade-off. To these ends, this study explores the structural characteristics of the drug-terror nexus in Turkey at the individual and network level by relying on the literature on dark/covert networks and using Social Network Analysis (SNA) approach. In that, key players and their formal roles (labor division) as well as their power (e.g., centrality, authority, influence, prestige), dependence (autonomy), and positions are examined to identify both the particular roles and positions occupied by PKK members in narco-terror networks and their influence on how these networks are structured. Moreover, given that the nature of the activity (e.g., aim, objective, motive), whether terrorist or criminal, is considered to have particular importance on how criminal networks at the crime-terror nexus prioritize security and efficiency-i.e., the "security-efficiency tradeoff"- it also identifies the overall structural characteristics, e.g., cohesion, connectedness, and centralization.

In regard to the aforementioned, this research fills a significant gap in the existing literature in the following respects:

First, as opposed to the bulk of the literature that dwells on geospatial analyses (See e.g., $[5,10,14])$, organizational level analyses examining the scale and scope of this nexus elaborate on how crime and terror intersect, converge, and diverge (See e.g., [10, 12]). This study focuses on the terrorist nexus (PKK members in drug networks) itself along with actor and network-level structural characteristics. As mentioned earlier, there exists no study empirically (by using SNA technique) examining the role and positions of PKK members in narco-terror networks in Turkey.

Second, despite the abundance of studies analyzing covert networks, empirical studies applying analytical network methods to observed data are relatively limited due to the difficulty in accessing such data [22]. Everton and Cunningham [29: 2] acknowledge that many of the studies on security efficiency characterization have been qualitative in nature and lack standard SNA measures. Moreover, as Zech and Gabbay [30: 215] underline, covert nature of clandestine/dark networks makes them difficult to study, and mapping out their internal structure - comprised of latent relations - makes this problem particularly acute, which reflects a discrepancy between theoretical and empirical SNA studies in the literature. As Crossley et al. [31: 3] point out, prior research on dark networks, in general, has been based mostly on simulations and theoretical models (e.g., [32, 33]). Very few studies in the literature have been based on first hand (observed) data (e.g., [16, 17, 20, 25, 31, 34-36]). This study uses a dataset coded from the Turkish government's official database, which includes multiple sources from different agencies as elaborated in data section. 
Toward these ends, this study first provides a brief literature review on the relation between terror and illicit drug trafficking followed by a literature review on structural characteristics of covert/dark networks and their prioritization between security and efficiency. Second, it briefly discusses the nature and characteristics of illicit drug trafficking and drug networks in the Turkish context. Third, it provides brief review on the PKK (e.g., historical emergence, evolution, strategy, goal, ideology, nature and characteristics) with a particular focus on its financial resources its relation with illicit drug trafficking. Fourth, it introduces the method and research design, in which it discusses the conceptual model, nature and characteristics of the data and it develops hypotheses. Fifth, it identifies related concepts in SNA and the operationalization of metrics used in this study (empirical model). Next, it presents findings at both, individual and network level and it discusses these findings by reviewing the prior research in the literature. Finally, it ends with concluding remarks.

\section{Literature review}

\section{Crime-terror (drug-terror) Nexus}

As crystallized in the links between Colombian drug cartels and insurgencies in the 1980s, "narco-terrorism" has been a growing concern across the world [5]. Schmid [37] reports that in almost thirty countries around the world there is a link between armed insurgent groups and drug trade. Piazza [13], based on an empirical large-n and crosscountry analysis (i.e., approximately 170 countries for the period 1986 to 2006, between 2868 and 3787 country-year observations per model), finds an association between illicit drug trade and domestic and international terrorism, thus concluding that the interdiction of narcotics would bring about security benefits in fighting against the threat of terrorism. Freeman [11], on the other hand, suggests that illicit drug trafficking is in one ("illegal activities") of the four main terrorist financing categories (others include "state sponsorship," "legal activities," and "popular support"); however, he notes that due to legitimacy concerns, terrorists reluctantly and, in most cases, indirectly resort to the drug business for generating funds. Thus, drug trafficking problems become more complex when linked to terrorism [5].

There exists a common approach to terrorism and narcotics trade: while the former is a politically driven phenomenon, the latter is primarily an economically driven and forprofit enterprise. This distinction has been reflected in the widely accepted motto "methods not motives." $[14,15]$. Despite this widely accepted discursive lens, some argue that while these two phenomena are ideally divergent in their end goal, the traditional distinction between the two has narrowed, and such an approach has become too restrictive and potentially misleading ([8]: 52). Therefore, the nexus between terrorism and crime reflects different types of relationships, such as temporary, parasitical, and symbiotic ([2]: 1104). Different types of relations between the two lie on a continuum where criminality and terror are placed on opposite ends. As Makarenko [3: 130-31] classifies, there are four distinct categories on the axis: alliances, operational motivations, convergence, and black holes. While discussions of these different types of relations are beyond the scope of this study, briefly, the most common type of relation is temporary, as argued by Hutchinson and O'malley [2: 1104], and/or 
reciprocal, whereby these networks borrow methods from one another, which is called method/activity appropriation ([8]: 53).

As for the specific connection between drug trafficking and terrorism, there exists an ambiguity about the existence as well as the nature and characteristics of the nexus ([5]: 112), which is a part of the focus of this research. There has been contention over the reasons and scope of terrorist groups' reliance on drug trafficking. Vargas [38] underlines this debate and states that while some considered terrorist groups' drug trafficking a mutation of their initial motive and betraying their ideology, others claim that terrorists refrained particularly from drug trafficking due to legitimacy concerns but resorted to other criminal acts such as extortion, kidnapping, and so forth. For instance, as Wang [9: 17] contends, terrorist groups' cooperation with drug cartels is due to ideological, cultural, and political differences between the two. Dishman [10] also argues that the difference in motives impede the cooperation between them. Shelley and Picarelli [8: 63], on the other hand, underline a more technical issue and note that terrorist organizations are pragmatic organisms and thus would integrate criminal acts into their supply chain to exploit criminal gangs' entrenched means rather than extending criminal methods themselves.

Based on the current evidence, the nexus between illicit drug trafficking and certain terrorist groups is not necessarily explicit. Asal et al. [24: 113-15] find only a limited connection between the two. However, terrorist groups might be involved in drug activity indirectly (a.k.a., unseen connection) and benefit from it $[11,13]$. In addition to direct involvement in production, processing, smuggling, and selling of drugs, terrorist organizations can be indirectly involved by offering certain services to drug traffickers related to facilitating their activity and/or taxing them for their services in return: e.g., protection of drug-cultivating farmers, provision of infrastructure and transportation, and so forth ([12]: 1274). These two phenomena explicitly coexist in socially and economically chaotic environments, which helps them strengthen their political and ideological influence [5, 39]. They both seek inaccessible locations with limited government visibility and/or control. Asal et al. [24: 113-15] find a direct relationship between ethno-national terrorism and illicit drug activity.

Moreover, the conceptualization of narco-terrorism as a term and the general characteristics of drug trafficking in Turkey need to be clarified. First, despite the fact that "narcoterrorism" is a widely used term, it has no standard definition in which different conceptualizations refer to different focuses and implications. While narco-terrorism originated in a context where drug cartels used terrorist tactics against law enforcement units to affect government's anti-drug policy, the term evolved over time to refer to different intersections ([5]: 306). For the purpose of this study, narco-terrorism is defined as terrorists' use of narcotics trade by either engaging in these drug networks or simply by directly appropriating the method of drug trafficking. According to this definition, a narcotic trafficking organization serves as a referent object of analysis in which the prime activity is the illegal trade of narcotics whereby terrorists resort to this activity for financial gains.

Second, illicit drug networks, like other criminal and terrorist organizations, do not reflect a standard character and vary in many respects - e.g., scale, form, structure, modus operandi-based on the factors originating from the geospatial conditions in which they operate - e.g., type of illicit drug to be trafficked, level of stability, border security, and nature of terrain in their habitat [2, 3, 40]. For instance, these organizations expand or shrink their activities and shape their organizational structures based on the 
aggressiveness of the law enforcement agencies, availability of regions to cultivate, and possible means for the production and transport of drugs. For instance, Colombian drug cartels (most of them linked to the Revolutionary Armed Forces of Colombia, FARC) or Afghan opium producers (most of them linked to the Taliban or Al-Qaida) reflect large organizations with some control over specific regions in the country [2, 3, 40]. However, drug networks in Europe, due to environmental conditions, are small in size and more underground in structure, reflecting their more decentralized nature [4]. Moreover, drug networks also vary based on their focus within the drug trafficking cycle (from pre-production, cultivation, production, storage, distribution), which also reflects changes in the level of the market that drug networks focus on [41]. In sum, the characteristics and structure of drug networks change according to the country and their social, economic, and political environments, reflecting different strategic needs and contextual contingencies ([40]: 430).

\section{Criminal (a.k.a. dark, covert) networks and structural characteristics}

Terrorist and criminal organizations have long been classified as "networks" due to changes in their structural characteristics ([40]: 417-18). Termed as dark, covert, underground, or clandestine networks, these entities no longer reflect a traditional state-bound hierarchical Weberian structure. These criminal and terrorist networks are replaced with international structures of networks that transcend borders, exploiting the lack of control in non-state spheres brought by globalization $([1,42]$; [43: 371]; [44: 89]). As Raab and Milward [40: 371-73] note, dark/covert networks do not have any standard form. Instead, they reflect various forms and shapes reflecting complex and overlapping structures depending on specific geospatial conditions that incur strategic needs and contextual contingencies in the environment in which they operate. Concurring this, Mayntz [44: 14] indicates the coexistence of "hierarchy" and "network" in terrorist organizations comprised of latent relations among members and depending on the environmental characteristics in which they exist. Overall, it is widely accepted that these crime and terror networks are highly flexible, pragmatic, and adaptable organisms that shape and transform their structure based on circumstantial factors [4, 40, 44].

However, what is considered to be vital in how covert networks are structured and operate is the interplay between secrecy/security and efficiency [20, 25, 31, 33, 34]. Known as the security-efficiency tradeoff, covert networks face an enduring dilemma in which they have to maintain security by staying secret to survive, while they have to ensure efficient communication and coordination-flow of information and resources - to accomplish their aims and objectives. More importantly, the nature of the activity (e.g., aim, objective, motive), whether terrorist or criminal, is considered to have particular differences on these networks' behavior in prioritizing between secrecy and efficiency [25]. Given this, the question arises: does such nature reflect any structural difference between terrorist and criminal networks since they diverge in motives and end goals despite sharing similarities in methods?

While both drug and terrorist groups are risk averse as far as security is concerned, Morselli et al. [25: 143-45] claim that they differ in certain basics of their operational character. While terrorist groups weigh security over efficiency, the opposite is true for drug groups, whereby they prioritize efficiency over security. This distinction makes them act methodically different: "time-to-task" is shorter for drug groups and longer for 
terrorist groups. They argue that notwithstanding the fact that security appears to be the predominant concern for all covert social groups, criminal networks are more efficiency-driven since they demand quicker returns than ideologically motivated groups, which prioritize security by trading it for efficiency. Given that drug networks are more flexible and pragmatic and easily replace one another $[20,36]$, they tend to opt for efficiency ([25]: 143). However, Crossley et al. [31: 3] argue that this might not always be the case because efficiency, i.e., quick return of material resources, is also very important to ideologically motivated networks, and the relative importance of secrecy and efficiency may vary depending on different temporality and actor characteristics. Thus, ideologically motivated covert groups view efficiency and secrecy as a compatible aim rather than a mutually exclusive one.

Concurring with Crossley et al. [31] and Baker and Faulkner [34: 850] claim that secrecy overrides efficiency for conspiracy networks. On the other hand, Erickson [45] reports the importance of pre-existing trust ties for covert networks to maintain their organizational security and argues that established drug networks prefer security over efficiency. Everton and Cunningham [29: 2] and Enders and Su [32: 54] underscore the temporality and dynamic nature of networks' response to this trade-off and argue that terrorist groups choose to reduce density in communication when faced with security threats, which leads them to substitute with different types of attacks entailing less coordination. Helfstein and Wright [46: 805-06], however, claim-by evaluating certain terrorist groups' attack networks - that these attack networks become increasingly dense as they get closer to the execution phase of their attack, implying the dynamic nature and temporal differences in covert networks' response to the trade-off. In the end, the results are mixed ([47]: 13). Everton and Cunningham [29: 2] particularly point out that covert networks seek to balance operational security and efficiency which culminates in temporally dynamic structure indicating shifting prioritization between security and efficiency in covert networks' operational process and life cycles. The dilemma and/or conflicting imperatives such as sought balance between secrecy and efficiency [25,31], or persistence and capacity, or differentiation and integration [20], or secrecy and communication [32] remain the driving forces for a dark network to design its structure and operations whereby they are subjected to a constant change based on shifting circumstantial factors and conditional dynamics ([31]: 3; [40, 45]).

Despite the aforementioned, network cohesion and connectedness (e.g., density-sparseness, geodesic distance, clustering) and organizational makeup (e.g., centralization-decentralization, power, structural holes, brokerage) are important indicators of dark networks' characteristics in security-efficiency trade-off. The general argument is that if a dark network emphasizes security over efficiency, the network structure is assumed to be sparse (low in density and short in average geodesic distance [average path length]) and degree decentralized, i.e., flattened and horizontally structured [34, 48]. More specifically, when decisions/information have to travel longer paths in the network, the chance of compromise increases, so the paths need to be shorter. This can be maintained through higher density and clustering into denser subgroups. But, in such case higher density causes another security risk with more visibility in action, which is to be minimized. To overcome this, the alternative is, inevitably, having a centralized hub that coordinates and controls all activities through direct contact ([33]: 15). This, however, causes another security vulnerability, namely that of elimination of the entire hub/cell/network when compromised. In short, as noted by Crossley et al. [31:2-3], while some scholars argue that low density and 
decentralization are more secure because when any actor is compromised, their potential damage to the whole network is minimized, other scholars suggest that high density or centralization lead to increased in-group solidarity and self-sacrifice and yield more trust and secrecy, by nature reducing the likelihood of compromise, defection, and infiltration [40]. Baker and Faulkner [34: 838] support the latter by claiming that while decentralization might seem to be the best alternative to maintain secrecy and efficiency (accomplishing complex tasks), higher centralization is necessary when a dark network requires secrecy and efficiency simultaneously. They further argue that illegal networks trade efficiency for security because they are primarily driven by the need for concealment rather than efficiency.

Sparrow [21] claims that high and low centralization can be balanced by having localized dense clusters (benefits of, e.g., motivation, solidarity, self-sacrifice, easy recruitment, and trust via pre-existing ties) in a globally sparse network chain (loose connections, minimized security risk of infiltration, and reduced damage when compromised). Concurring with this, Krebs [18] and Watts [49] underline the importance of small dense clusters reflecting small world characteristics in which these clusters, as Granovetter [50] claims, are tied to one another via "significant" weak ties, indicating the vitality of these loose connections when analyzing dark networks. However, the dilemma does not end here: while loose connections may lead to structural holes and less coordination between clusters, increased density and the degree of centralization of each cluster leads to more visibility of these clusters, then being more susceptible to detection. Therefore, there are strengths and weaknesses of different structures, yielding different compensations of density, centralization, path length, and clustering. In light of the aforementioned literature, studies on the general structural characteristics of covert networks reveal mixed results, reflecting higher and lower density and centralization figures for criminal and terrorist networks (See [17, 34, 51, 52]). The figures are elaborated upon in the results section and used as a benchmark to compare the findings from the sample networks analyzed in this study.

By the same token, claims on the degree of centralization of covert networks revealed mixed results. Natarajan [36] and Klerks [53], for instance, assert that drug trafficking-related illicit groups are decentralized. However, Baker and Faulkner [34]in their analysis of three conspiracy networks in the heavy electrical industry-find criminal networks reasonably centralized. Crossley et al. [31: 10-11], on the other hand, find that the average degree of centralization decreases and the number of isolates increases as networks became more covert. They further argue in their technical analysis that nodes reveal small dense clusters weakly tied to other ego networksshowing small-world characteristics - in suffragette networks in the UK. Overall, covert networks are found to be both centralized and decentralized ([47]: 8-9), having both strengths and weaknesses in terms of security and efficiency. Lindelauf et al. [33] for instance, argue that dark networks are more centralized when they are in a hostile environment, whilst with sparse structures. It should be noted that there exist certain technical and methodological reasons for the competing arguments on centrality and density of covert networks. As Everton and Cunningham [29: 2] point out, these mainly include measurement problem, e.g., resorting to a single centrality measures; omitting multi-relational nature of dark networks and failing to outline different types of relations - i.e., treating all different relations as a single type; and not accounting for the context and environment in which covert networks operate. 
Moreover, covert networks feature microstructures of clusters and cliques as well as core-periphery structures ([47]: 10), to balance strengths and weaknesses stemming from different structural characteristics ([31]: 4). For instance, Morselli et al. [25: 148, 152-53] argue that, as opposed to criminal networks that build outward from a core, terrorist networks lack a core and do not reflect core-periphery structures. Raab and Milward [40: 413-19] and Helfstein and Wright [46: 805-07] argue that terrorist networks might have cores that facilitate terrorist activities tied to specialized members on certain technical issues of finance, strategy, and planning.

In the end, one should note that there is no widely accepted specific threshold to deem whether a network is dense-sparse or centralized-decentralized [47]. This is because, as Crossley et al. [31: 3] suggest, networks might have multiplex structures in which scores of centrality, centralization, and density may vary among different layers of the network that are responsible for different types of activity and resources (e.g., money flow, drugs, information, and so forth). Therefore, covert networks may reflect both relatively more centralizeddecentralized and denser-sparser natures as a whole and/or in their micro-structures. This, however, may change depending on the context, temporality, layer, type of activity/action, objective, member characteristics, and other related circumstantial conditions in which the overall network or its particular segment/cell/subgroup operate ([31]: 4; [45]: 189; [47]: 11).

In terms of social characteristics, dark networks lean on pre-existing ties and social bonds known as "trust ties." [40,47] claim that pre-existing social ties increase network resilience. Jordan et al. [35: 36] argue that the covert networks are more socially restrictive based on pre-existing (familial and friendship) trust ties as they get smaller in size and, thus, the odds for security agencies to detect them is mitigated. Concurring with this, Crossley et al. [31:3] argue that trust ties and social bonds facilitate recruitment and self-sacrifice. This is because, as Sageman [43] and Erickson [45] assert, pre-existing contacts are important for the growth of network membership, which make social ties and trust-based relations inevitable. In support of this argument, Krebs [18] — in his analysis of the terrorist network behind the September 11 attacks - underlines that in order to develop reactive and proactive preventive measures, "trust ties" between and among members are to be identified in order to understand and disrupt a covert/dark network, which brings social bonds to the forefront. In short, as suggested by Milward and Raab [20: 349], covert networks are highly dependent on actors' pre-existing linkages. Actors are able to bond via shared values and norms as well as their ethnic backgrounds or tribal relationships in order to establish stronger and more resilient networks to exert power and authority against competitor networks in their respective market.

\section{Drug trafficking in Turkey}

Turkey has had drug trafficking problems for several decades. Its geographical location between the east and west coupled with its ongoing conflict with the PKK and subsequent socio-economic problems in the southeastern and eastern regions have made Turkey a perfect scene for drug traffickers [54]. Known as the "Balkan Route", this traditional heroin, morphine base, and acetic anhydrite route starts from Afghanistan and passes through Pakistan, Iran, Turkey, and the Balkans to reach its destination, namely, Europe [27]. In addition, there exits an alternative route that goes through the southern parts of Turkey, which passes through the Middle East, the Mediterranean Sea Islands, and the Balkans to Europe [55]. 
The Balkan Route has been a growing concern for European governments, which has become more active in the last decades. Most of the drug trade - through this route - in European nations in recent years has been controlled by Turkish drug traffickers [56]. According to the UNODC report [57], Turkish security agencies seized approximately $15 \%$ of total heroine in the world and European authorities reported that majority of these drugs originated in Afghanistan and that Turkey was on their transportation route. These figures reveal that drug traffickers have actively used drug routes passing through Turkey.

Moreover, social bonds due to historical ties do matter in Turkey-based drug trafficking activities. Kurds living in the region (Turkey, Iran, Iraq and Syria) share similar linguistic, cultural, and familial characteristics which promote communication and stretch ties across the borders. Likewise, Turkish ethnic groups living in Greece, Bulgaria, Macedonia, Kosovo, Bosnia, and Romania have relatives in Turkish cities of Istanbul, Bursa, Edirne constituting strong individual ties with the Balkan region [58]. Furthermore, many Kurds have moved to European countries for both economic and political reasons, constituting a large diaspora across the Europe [28]. In sum, over the years, Turkish territory has always been used as a transit route for drug trafficking into European countries, and Turkish illicit drug networks have benefitted from Turkey's geopolitical location $[1,4]$.

Characteristics of narco-terror and illicit drug networks in Turkish context Criminal networks do not reflect a standard character varying in many respects (e.g., scale, form, structure, modus operandi) based on factors originating from geo-spatial conditions in which they operate (e.g., type of illicit drug to be trafficked, level of stability, border security and nature of terrain in their habitat) $[1-3,40]$. For instance, these organizations expand, enlarge or shrink their activities and shape their organizational structures based on the aggressiveness of the law enforcement agencies, availability of regions to cultivate, possible means for production and transportation of drugs. Colombian drug cartels (most of them linked to the FARC) or Afghan opium producers (most of them linked to the Taliban or Al-Qaida) reflect large organizations with some control over some regions in the country [1-3]. However, drug networks in Europe, due to environmental conditions, are small in size and more underground in structure reflecting their more decentralized nature [4]. Drug networks also vary based on their focus within the drug trafficking cycle (pre-production, cultivation, production, storage, distribution) which also reflects changes in the level of market focus [41]. Overall, the characteristics and structure of drug networks fluctuate depending on the country with their social, economic, and political environment reflecting different strategic needs and contextual contingencies ([40]: 430).

Turkish drug and narco-terror networks, while changing overtime like others, are small-sized, pragmatic enterprises [58]. They are defined by their kinship and peer structures similar to their Russian and Caucasian counterparts. Also, like the Afghan and Tajik networks, Turkish networks have certain geographical advantages in supply and transportation through the Southeastern and Eastern regions of Turkey [27]. Most of the drug networks are involved in trafficking of illicit drugs which does not include pre-production, cultivation, and production processes [58]. Conclusively, Turkish drug networks are profit-oriented, small entities with rational, pragmatic, flexible, and fluid characteristics in which their structure and function are driven mostly by material incentives rather than reputation and endurance. 


\section{The PKK}

The PKK is the latest exemplar of Kurdish uprisings in Turkey which dates back to the Ottoman times. The PKK emerged in the 1970s, being a part of the 'new left wave of' inspirited political uprisings throughout many parts the world, most notably in Latin America. It was officially founded by Abdullah Ocalan in 1978. The armed struggle, however, was launched in 1984 in the Southeastern part of Turkey [59]. The decadeslong PKK insurrection is known to be not only as the bloodiest but also as the longest insurrection in modern Turkish history. Since the outbreak of its campaign, over 50,000 people lost their lives due to PKK violence which has been impacting the Turkish state in the political, social and economic realms [60].

Over the duration of the conflict, there has been a strategic tit-for-tat between Turkey and the PKK that has led changes in the characteristics on the conflict. For instance, while the PKK embraced Maoist strategy with a more direct challenge seeking territorial separation in its initial years, PKK resorted to more asymmetric and indirect means pursuing an autonomy after the mid 2000s (some form of power share). Acknowledging its military defeat in 1994 (in direct fight), the PKK was able to shift to other strategies as an adaptive insurgent organization [59]. PKK renounced its topdown approach for territorial separation and embraced a bottom-up approach which has been defined by social and political activities [61]. Ocalan, who has been incarcerated in İmralı Island since his capture in 1999, shifted from a separation to a, what he calls, 'Democratic Confederalism' in Turkey's east and southeast regions that are heavily populated by Kurds. Within this bottom-up approach the PKK founded an umbrella organization, the Kurdistan Communities Union (Koma Civaken Kurdistan, KCK) in 2007, that covers pro-PKK ideology in the wider region including PKK's branches in Iraq, Iran, and Syria. The PKK has maintained its threat level by exploiting the dynamics of asymmetrical warfare (i.e., 'indirect challenge' by targeting Turkey's will to fight) — as evidenced by subsequent terms' escalating PKK violence [61, 62].

Having perceived the costly deadlock and hurting stalemate in 2007, Turkey embraced a conciliatory approach and conducted two short-lived resolution attempts: Kurdish Opening in 2009-2011 and Resolution/Peace Process in 2013-2015 [60]. Once the latest resolution attempt was disappointedly crippled in mid-July 2015, violence returned immediately. Tensions in today's Turkey are at their peak. This is due mostly to the latest developments brought by the Syrian Civil War in the Middle East. The territorial control of northern Syria by the PKK's Syrian branch, The Democratic Union Party (PYD), particularly, increased Turkey's ontological security threat perception towards the rise and consolidation of proPKK Kurdish entities in the region - in both political and military terms [62].

Nature and characteristics of the PKK Studies in the literature have described the PKK with different terms, such as terrorist organization, insurgency movement and/or Kurdish guerillas or rebellious group. Such heterogeneity in defining the PKK resulted in using different concepts when studying the PKK. Literature on this contentious issue provides multi-perspective approach and particularly distinguishes the actor-oriented and actionoriented approaches, which suits well to the case of the PKK. Ünal [26], in an empirical study, argues that while the PKK indicates an insurgent character as an actor, its use of violence reflects intense terrorist action, particularly after its military defeat in 1994, when the PKK shifted to revolutionary terrorism from a direct guerilla fight [61]. Yet, PKK's use 
of terrorism temporally overlaps with its guerilla methods and resulting from different factors and reasoning at the intermediate level, the PKK's terrorist and insurgent violence are designed to supplement for the overall aim of the PKK's political campaign, namely coercing Turkey into a political compromise, i.e., a negotiated settlement.

Financial resources and PKK's nexus with illicit drug trafficking The PKK has been provided with either logistical and/or psychological support from Kurds in and out of Turkey. In order to wage its politico-military campaign, the PKK has systematically engaged in other means, mostly organized criminal activities, to financially support these activities [4, 27, 28, 56, 63]. The vast majority of financial support came from fund raising activities in Europe $[56,64]$ where the PKK relies on large a supporting population (e.g., Germany, Holland, Italy). In its heyday in the early 1990s, the PKK accumulated $\$ 86$ million (U.S.) annually from its diaspora in Europe [63]. In late 2000s, this figure reached over \$500 million (U.S.) a year [27]. Another major income source for the PKK is illicit drug trafficking [3]. The PKK has been known to have a large web of heroin traffic from Southwest Asia into Europe $[1,4]$. PKK is connected to nearly $80 \%$ of illicit drugs in Europe [27]. While the PKK is connected to different cycles of the narcotics trade, i.e., from production to retail distribution, the bulk of the illicit drug trafficking includes the distribution cycle with a wide network that lies in between Asia and Europe. In most cases, PKK provides safety for traffickers (e.g., from Iran and Afghanistan to Europe via Balkans) and takes its share and sometimes tax traffickers. The PKK exploits the geographical advantages in the far southeastern part of Turkey, which is closely located to the major narcotics sources of South Asia and Central Asia [56]. PKK's share in drug trafficking shifts upward annually. According to the UNODC report, PKK gains US\$50 million to US $\$ 100$ million annually from heroin trafficking alone and several PKKaffiliated traffickers were arrested in Europe [57].

PKK has also been involved in arms-smuggling and human trafficking (from Iraq and elsewhere in Asia into Europe), mostly of illegal workers [27, 56]. In addition, PKK used extortion to collect money from Kurdish landlords and businesses in a routine manner through the use of force when necessary, called "taxation". The PKK has also been involved in illegal arms trade [64]. Curtis and Karacan [56] reported that the PKK supplied arms to other Kurdish terrorist groups and to the Tamil Tigers of Sri Lanka. The PKK does not publicly recognize its trafficking activities for legitimacy concerns. However, the PKK uses funds gained from illegal activities, including narcotics trade, for providing social services and financially helping its supporting population to increase its legitimacy, and thus, its popular support [65].

\section{Method and data}

\section{Data}

This study uses secondary data that were extracted from official government records by Turhal [58] for his research. The data used in this study is comprised of randomly selected five narco-terror cases out of 50 narco-terror cases that were randomly selected from the PKK related narco-terror case pool of the Turkish Anti-Smuggling and 
Organized Crime Department database by Turhal [58]. As Krebs [18: 15] argues, SNA data should identify two sets of information to plot an accurate picture of a covert network: task and trust. The "task" includes all logs and records of telecommunications (including internet), travels, intelligence data from surveillance, and infiltration as well as public and court records. "Trust" includes prior contacts in family, schools, clubs, and other organizations. Yet, as underlined by McGloin and Kirk [19: 171] and Van der Hulst [22:116], SNA data is based on relational ties, and it can be based on various different sources.

The dataset used in this study covers a wide array of sources reflecting information on trust and task. As elaborated in Turhal's study [58], the dataset was archived by different security agencies and entities within the entire span of investigation and prosecution processes. These include documents from law enforcement and criminal intelligence units and court trials. Therefore, the data are coded from multiple sources, such as police reports, surveillance records including physical (i.e., face-to-face meetings, courier-based interaction) and electronic sources (i.e., phone calls, internet connections), wiretaps (i.e., content analysis), offender statements, court records/proceedings, and other related documents placed in the official records.

Case files were particularly useful to elucidate in-group relations, key players, and the flow of communications, since the files include information on latent relations between and among network members (for more detail please see [58]). As explained by [58], the network data are coded according to interactional criteria consistent with the SNA method using coding techniques that are described in several resources that include [66-68]. These include the transactional content measure, exploring the exchange of information and resources within the relations between offenders in networks. As reported by Turhal [58], demographic information and social characteristics (e.g., kinship and peer/friendship structures, age, education, occupation, marital status, nationality) are coded from offender statements (as part of the police investigations and court processes), the majority of the network data (relational ties) related to operational and organizational structure was taken mostly from surveillance reports prepared by law enforcement units during the investigations, wiretaps and offender statements in court documents, and reports from police case files. Police case summary reports and surveillance reports were particularly useful to elucidate in-group relations, key players, and flow of communications since they include information on latent relations between and among network members (Turhal, 106-107). Yet, in certain cases, there existed information on organizational structures of these networks resulting from the law enforcement investigation units that helped identifying the roles, structural distribution of network members ([58]: 108).

The data include the symmetrical relations (adjacency matrix) based on interactions reflecting "ties" in binary network data $(0-1)$ as well as valued network data indicating the strength of ties on a one-three scale, i.e., weak, moderate, and strong. The valued data is used when plotting sociograms, which underline the strength of ties represented through bolder lines and arrows. In the end, the data has a one-mode symmetric (nondirectional/undirected) nature.

It should be noted that there are certain limitations on the SNA data in general and the dataset used here in particular. As Van der Hulst [22: 110] argues, compiling complete network data for dark networks is very difficult since these networks are ontologically underground. Sparrow [21: 261-63] underlines this by underlining the element of 
"incompleteness" indicating missed links, "fuzzy boundaries" referring to unclear borders of covert networks, and the "dynamic" nature of network structures over time. As Zech and Gabbay [30: 215] pointed out, and mapping out internal structurescomprised of latent relations - of covert networks is particularly an acute problem leading to a discrepancy between theoretical and empirical studies. For the fuzzy boundaries, in particular, the capabilities of SNA in relation to small group networks is critical ([69]: 104-105). It should also be noted that size of the sample networks analyzed here is small and network metrics, such as density, average nodal degree, clustering coefficient and etc., will vary greatly in networks of small size in adding/ deleting a link/node. However, this study used multiple metrics to overcome this concern. Yet, data used here reflect only static representation of structural characteristics and do not include temporal changes when coded by Turhal [58]. Moreover, as reported by Turhal's [58: 100-107] research, certain inconsistencies in data sources exist-where the data were extracted - since there is no uniform reporting template for Turkish law enforcement units.

However, as Van der Hulst [22: 116] and Bright et al. [51: 153] bring to our attention, having access to agency records is novel due to having alternative inquiries on information related to relational and structural patterns of dark networks. Seen in this light, the data used in this study were extracted from government databases and, thus, contains a wide array of data sources that enable the verification of relational ties as reported by Turhal [58: 100-107]. More importantly, as reported by Turhal [58] who collected and coded the data, two external researchers coded samples to conduct interrater reliability tests by using the percentage agreement method ([58]: 109-111). The results reflected only insignificant differences in coding the information stored in the extracted case files, which indicates no systematic bias stemming from the coding process ([58]: 107-121).

\section{Conceptual model}

By questioning sampled narco-terror (PKK) networks' structural characteristics at individual and network level, this study addresses the below research questions:

- "How PKK members are positioned and what roles are taken by them in PKK affiliated narco-terror networks in Turkey?"

- "Whether or not having PKK members, as terrorists/insurgents in these narco-terror networks, made these entities structurally more security driven than efficiency?"

To address these questions, it first identifies the formal roles occupied by PKK's armed militants and how these members are positioned in these PKK-involved drug networks. While roles are identified through offender statements, surveillance reports, court files, structural positions are identified through related SNA metrics.

Roles As suggested by many scholars [19, 21]; [22: 116]), identifying key players, their roles, and their positions in the network is vital to better understanding the relational patterns and structures of covert networks. However, there is no literature on formal role distributions within drug networks [51]. Formal roles and labor divisions in covert networks vary in different contextual dynamics of different geopolitical regions 
depending on the conditions (e.g., type of drug, cycle of trafficking activity [e.g., production, dissemination]) and cultural environment in which they operate $[41,52]$. Given these, labor divisions in sample narco-terror networks reflect certain differences in role distributions. Despite their small size (the sample networks averaged 14.8 members), sample narco-terror networks include various roles assigned to different members working within various layers of the operation. There are three recognizable hierarchical layers in sample networks, strategic, tactical, and operational levels. For the purpose of testing the aforementioned hypothesis, only strategic level roles and terrorists are identified and discussed within their positions.

Strategic level offenders in sample drug networks constitute the central command structure and typically include organizational leaders (ORL) and high-level managers (HLM) underneath, referring to core actors initiating and controlling trafficking activity. The ORL is the crime initiator and final decision maker. HLMs play a brokerage role between other layers, and they actually plan, design, and control trafficking activities. Many studies used similar role classifications (e.g., see [22, 31, 36, 51]). In the context of the Turkish narcotics trade, the HLM is used as an assistant to the ORL to mediate between lower levels of tactical and operational level offenders. Leaders and managers were identified through police surveillance reports and offender statements. As will be seen later, despite the fact that ORLs are clearly identified in most of the samples, ORLs in certain cases were not identified based on the source material. The significance of the role of drug providers (DP) was also identified, which refers to the members who supply the illicit drugs to be trafficked. She/he is mostly tied to strategic level offenders. While in certain cases DPs can be the leader or high-level manager, in other instances, she/he is an outsider and not even part of the network and thus might be an isolate[s] selling drugs to the organization in a one-off manner. Thus, the positions of ORLs and HLMs are analyzed as key players, while DPs are only identified.

Terrorists ${ }^{1}$ denotes offenders who are members of the PKK. Terrorists are identified based on different evidence including prior records, offender statements (confession), reports from criminal intelligence units in police case files, and so forth. Linkages to the PKK include physical support and involvement in PKK activities, financial support in the form of money transfer to PKK members, and possession of illegal documents related to the PKK. The nodes referring to PKK members are denoted with the prefix " $T$ " and blue color to be easily recognized in sociograms and tables (e.g., T12 or T5-HLM).

Positions For identifying the structural position of terrorist nexus, it first examines the power and centrality (prestige and influence) of PKK militants through their actor-level scores in the categories of closeness, betweenness, "coreness," and so forth (e.g., sociograms). It does so to identify how central and/or influential their positions are in order to elucidate the form and the nature of the terrorist nexus within narco-terrorist networks. Second, it analyzes the overall structural characteristics (topography), cohesion and connectedness (density, geodesic path distance, clustering coefficient, transitivity), centrality, and group centralization of these narco-terrorist networks to explore

\footnotetext{
${ }^{1}$ The term "terrorist" is used to comply with and keep the consistency with the literature on crime-terror nexus. PKK's characteristics in the concepts of terrorism and insurgency is briefly discussed in literature review section.
} 
the relative need for secrecy and efficiency to address whether or not PKK members make these networks structurally more security driven.

With regard to how the PKK members (the terrorist nexus) influenced these networks' structural characteristics that reflect their reliance on security or efficiency, this study tests certain main arguments made by empirical (e.g., [18, 25, 31, 45, 46]) and theoretical analyses in the literature $[32,33]$. In this regard, by leaning on the lit review above, this study hypothesizes that involving PKK militants (the terrorist nexus) generally makes the structure of narco terrorist networks more security oriented as argued by Morselli et al. [25] In that, it hypothesizes that:

- "key players are positioned more in the periphery than the core (for concealment and security)"

- "sample narco-terrorist networks, as having terrorist nexus, are sparse"

- in the same regard, "sample narco-terrorist networks are decentralized"

- "the flow of information in sample networks has long path length and tend to be less clustered in tight-knit subgroups reflecting less coreness"

- "these networks have strong trust ties (to maintain group solidarity against infiltration and defection)."

\section{Empirical model and analysis technique}

This study uses SNA technique, which is widely used to examine structures of social networks and to identify relational patterns between and among entities, e.g., individuals, groups [66-68]. SNA is a particularly effective tool to explore and understand power and dependence in social roles, positions, and centrality of individuals as well as exploring the overall cohesion, connectedness, and structural characteristics of covert networks ([19, 21]; [22: 116]).

The use of SNA in understanding criminal and terrorist networks, as largely stimulated by Sparrow's [21] seminal work, has also led academics to make structural inferences on criminal and terrorist groups as dark/covert networks. Sparrow [21: 252] underlines critical questions that criminal intelligence units need to identify when trying to disband a criminal network: Who is central to the network? Whose elimination would sever the drug supply? Which members of the network appear to be aliases? What role or roles does a specific individual appear to be playing within a criminal organization? In this context, this study conducts SNA to explore and decipher the nature and form of the terrorist nexus. It examines terrorists' roles, positions, power, dependence, and influence and their associated importance in narco-terror networks in Turkey. In that, it uses the following SNA metrics:

Density reflects the degree of connectedness (network cohesion) among members of a network. Denser networks mean more incidences among members and in dense networks it is easier for people to monitor the behavior of others (policing each other) and prevent defection. Formally density measures the cohesion/connectedness of a network through the total number of observed ties within a network divided by the maximum possible number of ties ranging from 0.0 to 1.0 [70]. Average nodal degree is a supplementary metric to density estimating social connectedness, determined by 
calculating the average number of lines/neighbors each node/actor has ([66]: 101-3). Higher average nodal degree indicates a more intense relationship. Average Geodesic Distance is simply the average length of the shortest path between two actors [70]. The geodesic path(s) is considered to be the "optimal" connection between two nodes/ actors, indicating how close actors are together ([68]: 81). The smaller the distance, the more connected the actors are in the network. Clustering Coefficient measures the average densities of neighborhoods of all actors in a network, identifying the existence of densely knit clusters (clique-like tight groups), known as the small world phenomena [49]. Transitivity measures the completed triads meaning that two nodes in a network that are connected by an edge (line) are transitive ([68]: 93). The higher the percentage, the more transitive (completed triads in peripheries) the network is.

Degree centrality is the count of the number of an actor's adjacent direct relational tie(s), indicating that the more direct ties an actor has, the more central and powerful that actor is within the network $[67,70]$. Likewise, the overall degree centrality for the network indicates the average score of all members' degree in the network. Closeness centrality indicates how close/far each actor is to all other actors in a network according to the average path distance to explore the ability or autonomy of the actor [70]. It measures the ability of a network member/node to reach other members/nodes in the minimum number of steps [35]. So, average closeness (normalized percentage) indicates how actors are close to each other. For actor-by-actor scores, higher index refers to more distance (farness) of an actor from others. For network level average, normalized percentages are used (as for the network level average betweenness and degree centrality), and higher index refers to more closeness. Betweenness centrality estimates the extent to which each actor lies on the shortest path between all other actors in a network. This metric measures the intermediate positions of actors for coordinating and controlling relationships in the network and higher index refers to more intermediation ([66, 67; [70: 15]). It simply denotes the frequency of one node appearing between two other nodes [35]. Constraint (Control and Structural Holes) measures the involvement of actors to incomplete triads. Low constraint means more structural holes offering a brokering options/positions to the actor (to broker the flow of information and resources) and vice versa ([70]: 154). Multiplicative Coreness (continuous) uses a 0-1 index to indicate how an actor is close to or correlated with a core preference pattern. An index score closer to 1 means increased correlation with core pattern. Coreness indicates a single individual's (node) position vis-à-vis a core in the network. Coreperipheriness (correlation) is a coreness metric for the overall network, indicating the correlation between tie strength and joint centrality to measure core-peripheriness. The index is higher if central actors tend to have strong ties with each other, while peripheral actors tend to have weak ties (for all pairs of nodes) with one another [71].

Group centralization measures analyze the generic characteristics and makeup of networks. These include, for instance, the degree of group-level centralization that examines how centralized/hierarchical or decentralized/flat a network structure is on a 0-100\% scale (normalized scores are used for comparison purpose), in which more variation (meaning few actors with high centrality scores) yields higher network centralization scores [70].

In addition, sociograms (graphic representation of social links in a visual network structure) are plotted to supplement the general understanding about these networks. The size of nodes (actors) and labels in sociograms are developed based on networks' 
betweenness attributes (as a measure of centrality and power) to identify pivotal players and nodes that have kinship structures. The lines and arrows indicating the ties between offenders are adjusted according to the strength of the relationship (based on the valued data). All analyses are conducted, and the results are plotted using the UCINET and NetDraw software.

\section{Results}

This section first provides brief overview on the profile of members in the sample networks. Second, it introduces each sample networks and elucidates the role, power, and dependence of PKK militants with actor-by-actor scores of degree, closeness, and betweenness centrality, constraint, and coreness. Next, it discusses network level centrality and cohesion metrics to complement actor-level scores. It also plots sociograms for each of the sample networks to visually lay out PKK militants' positions as well as overall structures. The results for specific hypotheses on the security-efficiency trade-off are provided in the next (Discussions) section.

Sample cases involve trafficking of different types of drugs such as heroin, hashish, marijuana, and morphine base. The sample of five different illicit drug networks includes a total of 74 criminal offenders. Out of 74 traffickers, 18 were PKK militants operating in sample narco-terror networks. Out of these 74 members, 11 of them are Iranian and rest are Turkish. Except one, all members are male with an average age of 34 and majority of the offenders are married. Sample narco-terror networks mostly consist of individuals with low level of education. Out of 74 offenders, only 3 have college degree and rest of them has lower level of education. Sample networks yield strong trust ties in which, $33.3 \%$ of offenders have blood ties, while 56.2 have preexisting trust-ties.

Network\#01 This case refers to a 21-member network, 10 of whom are Iranian, trafficking morphine base from Iran to Europe through Turkey. ${ }^{2}$ Only two members, T-20 and T6-ORL, are linked to the PKK. As plotted in the sociogram (Fig. 1), network \#01 has a polycentric structure with two separate dense subgroups that are tied to one another through the key players. In each sub-group, core and clique-like dense relations exist with shorter distance, evident in a relatively higher clustering coefficient (0.64) and transitivity (22.61) as depicted in Table 7, and strong ties (bolder lines) as indicated in Fig. 1.

There exist four key players, one of whom is the leader, T6-ORL, linked to the PKK. T6-ORL plays a critical brokerage role between the two main clusters as evident in the highest (actor level) betweenness (56.633), lowest farness (37), and one of the lowest constraint (0.379) as plotted in Table 1 . This indicates the importance of his position for the efficiency and survival of the network, in which his removal would structurally destabilize the bulk of the network. The other terrorist, T-20, is directly tied to T6-ORL and is positioned in one of the cores having direct ties (degree) to his trust ties (kinship structures). In addition to the terrorist (T6-ORL) leading the network, there are three more key players (11-HLM, 13-HLM, and 8-HLM) who have critical brokerage

\footnotetext{
${ }^{2}$ The PKK not only has a branch in Iran, but its workforce also contains Iranian, Iraqi, and Syrian nationalities (for more information please see [28]).
} 


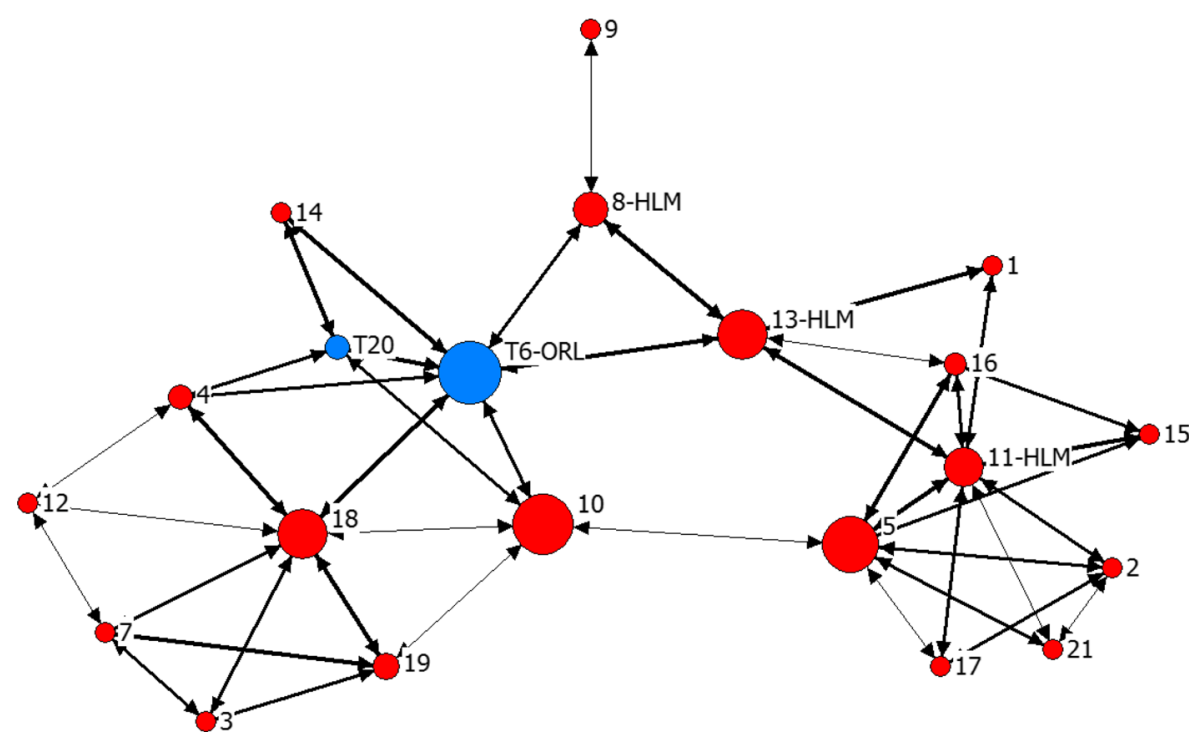

Blue color and prefix "T" denote PKK militants

Red color nodes denote other offenders/traffickers

"ORL" refers to organizational leader

"HLM" refers to high level managers

Fig. 1 Sociogram for network \#01

(betweenness) or pivotal (degree centrality) positions to effectively control and coordinate the communication and activities between different subgroups, and at the same time constituting structurally weak points.

Overall density is 0.20 with two weakly tied separate clusters indicating very high average betweenness centrality (77.19\%) as depicted in Table 6. A high average nodal degree of 4.09 and a relatively short average geodesic distance of 2.47 indicate high connectedness/transitivity in each of the sub-groups (Table 7). In line with this, strong kinship structures are denoted with yellow nodes in Fig. 1, in which, for instance, actors 19 and 18 are brothers, and the leader, T6-ORL, is the son of actor 14. In light of these, the terrorist nexus reflects a critical position and role in the network, despite this however, network \#01 is more efficiency driven than security given dense polycentric structure with short paths. Hence, except two Iranians, all network members were captured and arrested.

Network\#02 This case refers to an all Turkish, 17-member network, two of whom are terrorists (T5-HLM and T3-ORL), constituting the nexus. This network was involved in trafficking heroine and morphine base. Table 2 plots actor-by-actor scores. As seen from the table, both terrorists have strategic level roles: one being the leader (T3-ORL) and the other being the high-level manager (T5-HLM). Terrorists reflect the highest power by their degree centrality (6 and 5, respectively) and betweenness ( 82 and 46), indicating that they have the highest number of direct ties to others and they lie on the shortest path between all other actors (Table 2). They reflect central hubs with high brokerage roles as seen in Fig. 2. 
Table 1 Network \#01 - Actor-by-actor power and centrality scores

\begin{tabular}{llllll}
\hline Node & Degree & Between. & Close. & Constraint & Coreness \\
\hline 1 & 2 & 0 & 52 & 1.125 & 0.141 \\
2 & 4 & 0.333 & 53 & 0.74 & 0.296 \\
3 & 3 & 0 & 58 & 0.926 & 0.031 \\
4 & 4 & 5.817 & 49 & 0.642 & 0.053 \\
5 & 7 & 48.683 & 41 & 0.399 & 0.459 \\
T6-ORL & 7 & 56.633 & 37 & 0.379 & 0.119 \\
7 & 4 & 1 & 57 & 0.704 & 0.036 \\
8 -HLM & 3 & 19 & 46 & 0.611 & 0.063 \\
9 & 1 & 0 & 65 & 1 & 0.011 \\
10 & 5 & 53.75 & 37 & 0.451 & 0.142 \\
$11-$ HLM & 8 & 25.367 & 44 & 0.372 & 0.553 \\
12 & 3 & 0.7 & 57 & 0.84 & 0.031 \\
$13-$ HLM & 5 & 40.483 & 39 & 0.482 & 0.219 \\
14 & 2 & 0 & 55 & 1.125 & 0.033 \\
15 & 3 & 0 & 54 & 0.926 & 0.248 \\
16 & 4 & 3.45 & 48 & 0.704 & 0.288 \\
17 & 3 & 0 & 54 & 0.926 & 0.249 \\
18 & 7 & 39.967 & 41 & 0.412 & 0.084 \\
19 & 4 & 7.783 & 49 & 0.704 & 0.053 \\
T20 & 4 & 5.033 & 46 & 0.684 & 0.063 \\
21 & 3 & 0 & 54 & 0.926 & 0.249 \\
\hline
\end{tabular}

The terrorists-T5-HLM and T3-ORL-constitute hubs tied to one another, with offenders directly and only connected to them to strictly control the flow of information and resources as evident in the star-like network structure. Such a structure reflects fewer ties (sparse) to maintain security. For a network size of 17, the average geodesic distance of 2.94 can be deemed higher compared to other sample networks, indicating increased distance and therefore assured security, which is also evident in the lowest density score (0.13) and clustering coefficient (0.17). However, such a structure constitutes structural holes in which two terrorists have strict control over the entire flow of information and resources (constraint scores of 0.2 and 0.22 , respectively). As shown in Fig. 2 (yellow nodes) and in Table 8, \#02 has strong trust ties.

In the end, while the network structure indicates a central hub dominated by the terrorist nexus. Terrorists exert authority and strict control over the flow of information with fewer incidences among members. As suggested by Lindelauf et al., (2009) to be optimal for dark networks operating in hostile environments in their initial stage of operation. All members were captured and arrested.

Network\#03 This case refers to an all Turkish, 14-member network, two of whom are terrorists, trafficking heroine. As opposed to other NTNs, these terrorists are positioned on the periphery acting as DPs. The organizational leader is not identified in the 
Table 2 Network \#02 - Actor-by-actor power and centrality scores

\begin{tabular}{llllll}
\hline Node & Degree & Between. & Close. & Constraint & Coreness \\
\hline 1 & 1 & 0 & 63 & 1 & 0.005 \\
2 & 1 & 0 & 63 & 1 & 0.005 \\
T3-ORL & 6 & 82 & 29 & 0.223 & 0.905 \\
4 & 3 & 29 & 48 & 0.333 & 0.032 \\
T5-HLM & 5 & 46 & 36 & 0.2 & 0.175 \\
6 & 4 & 45 & 36 & 0.25 & 0.169 \\
7 & 1 & 0 & 51 & 1 & 0.028 \\
8 & 1 & 0 & 51 & 1 & 0.027 \\
9 & 2 & 8 & 43 & 0.5 & 0.056 \\
10 & 2 & 15 & 49 & 0.5 & 0.028 \\
11 & 2 & 0 & 40 & 0.785 & 0.183 \\
12 & 1 & 0 & 44 & 1 & 0.15 \\
13 & 1 & 0 & 64 & 1 & 0.005 \\
14 & 3 & 39 & 37 & 0.512 & 0.188 \\
15 & 1 & 0 & 44 & 1 & 0.15 \\
16 & 1 & 0 & 51 & 1 & 0.028 \\
17 & 1 & 0 & 51 & 1 & 0.028 \\
\hline
\end{tabular}

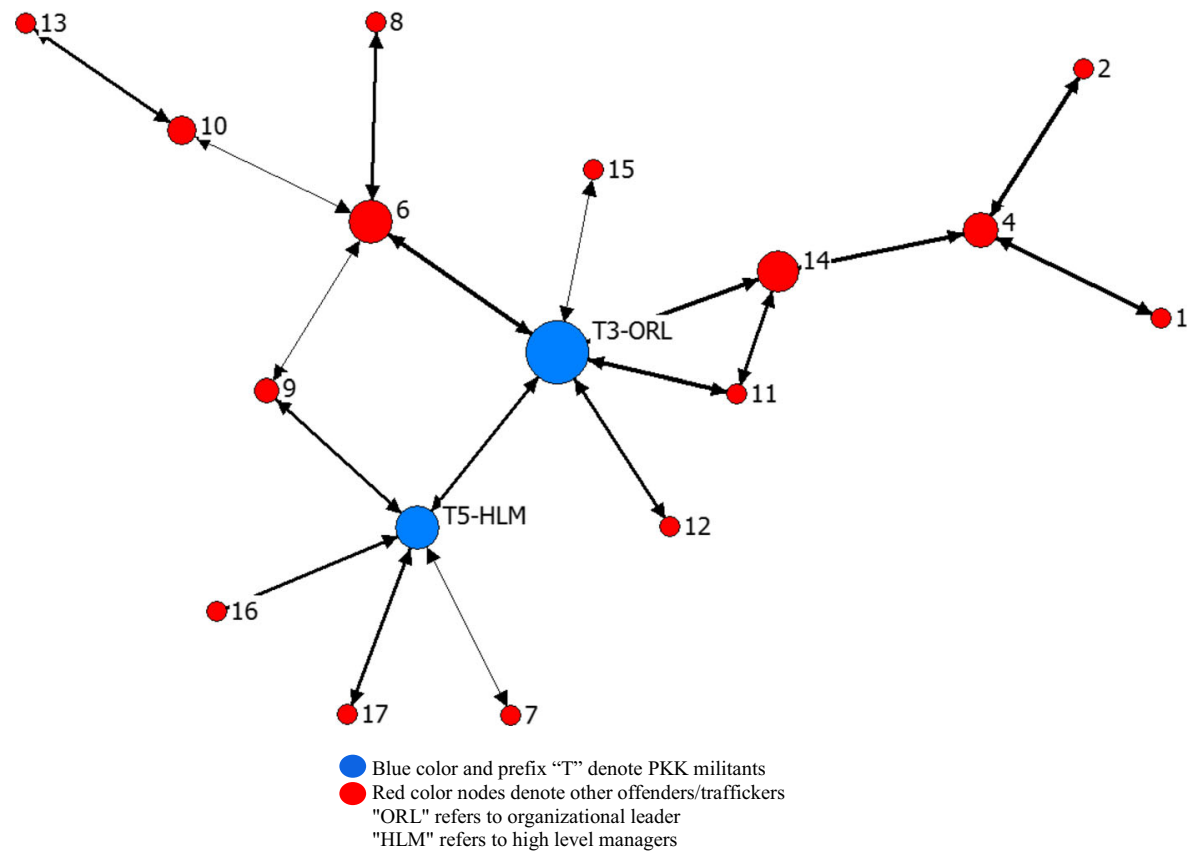

Fig. 2 Sociogram for network \#02 
Table 3 Network \#03 - Actor-by-actor power and centrality scores

\begin{tabular}{llllll}
\hline Node & Degree & Between. & Close. & Constraint & Coreness \\
\hline 1 & 3 & 0 & 24 & 0.926 & 0.236 \\
2 & 1 & 0 & 34 & 1 & 0.042 \\
3 & 2 & 0 & 26 & 1.125 & 0.179 \\
4 & 1 & 0 & 33 & 1 & 0.05 \\
5 & 2 & 0 & 26 & 1.125 & 0.114 \\
6 -HLM & 5 & 12.667 & 21 & 0.514 & 0.288 \\
7 & 8 & 21.417 & 18 & 0.361 & 0.43 \\
8 & 5 & 4.5 & 23 & 0.513 & 0.222 \\
9 & 2 & 0 & 26 & 1.125 & 0.179 \\
$10-D P$ & 9 & 28.667 & 17 & 0.333 & 0.576 \\
T11-DP & 4 & 0.25 & 24 & 0.74 & 0.227 \\
T12-DP & 4 & 0.25 & 24 & 0.74 & 0.227 \\
13 & 4 & 0.25 & 24 & 0.74 & 0.227 \\
14 & 4 & 12 & 22 & 0.583 & 0.244 \\
\hline
\end{tabular}

available data; however, there is a high-level manager (6-HLM) positioned on the periphery, and one of the three DPs, 10-DP, has a central position: highest degree centrality 9 , betweenness 28.667 , coreness 0.576 , lowest farness 17 , and lowest constraint 0.33, as depicted in Table 3. As shown in Table 7, the overall network indicates more reliance on efficiency with a high clustering coefficient (0.71), short paths (average geodesic distance of 1.88), and high connectedness, with 3.85 average nodal degree. The sociogram (Fig. 3) indicates that network \#03 has a core (core-peripheriness of 0.56 ) around 10-DP with complete triads (transitivity of 21.25\%) as reflected in Table 7.

The terrorist nexus in this network reflects weak position on the periphery but has the role of providing drug to be trafficked. Terrorists members T12-DP and T11-DP, also reflect a clique with strong trust ties (bolder lines in the sociogram) as depicted in Fig. 3. This is quite normal given that T11-DP is the brother of T12-DP and uncle of 13. The overall network structure seems to indicate more reliance on efficiency given short paths with more ties attached to the core and at the periphery. In the end, nine of the 14 were arrested, while the other five are fugitives, including the two terrorists.

Network\#04 This case represents an all Turkish network trafficking hashish and heroine. It has more terrorists than drug offenders: out of 12 members, seven were linked to the PKK. No leader is identified; however, two of the terrorists (T2 and T8) have critical positions (gateway, brokerage), connecting two subgroups. The 12-HLM, as the only key player, is positioned in the periphery. Almost all members (11 out of 12) had friendship ties before the network was formed, and there exist kinship ties among four members, two of whom are terrorists, as the yellow nodes denote in Fig. 4.

The nexus has important position in this network. In that, T2 has a pivotal role with the most ties and shares high betweenness scores with T8 (34 and 26, respectively). They act as a gateway between two clusters, constituting structural holes (constraint scores of 0.457 and 0.469 ), as depicted in Table 4 . The subgroup around T2 indicates a 


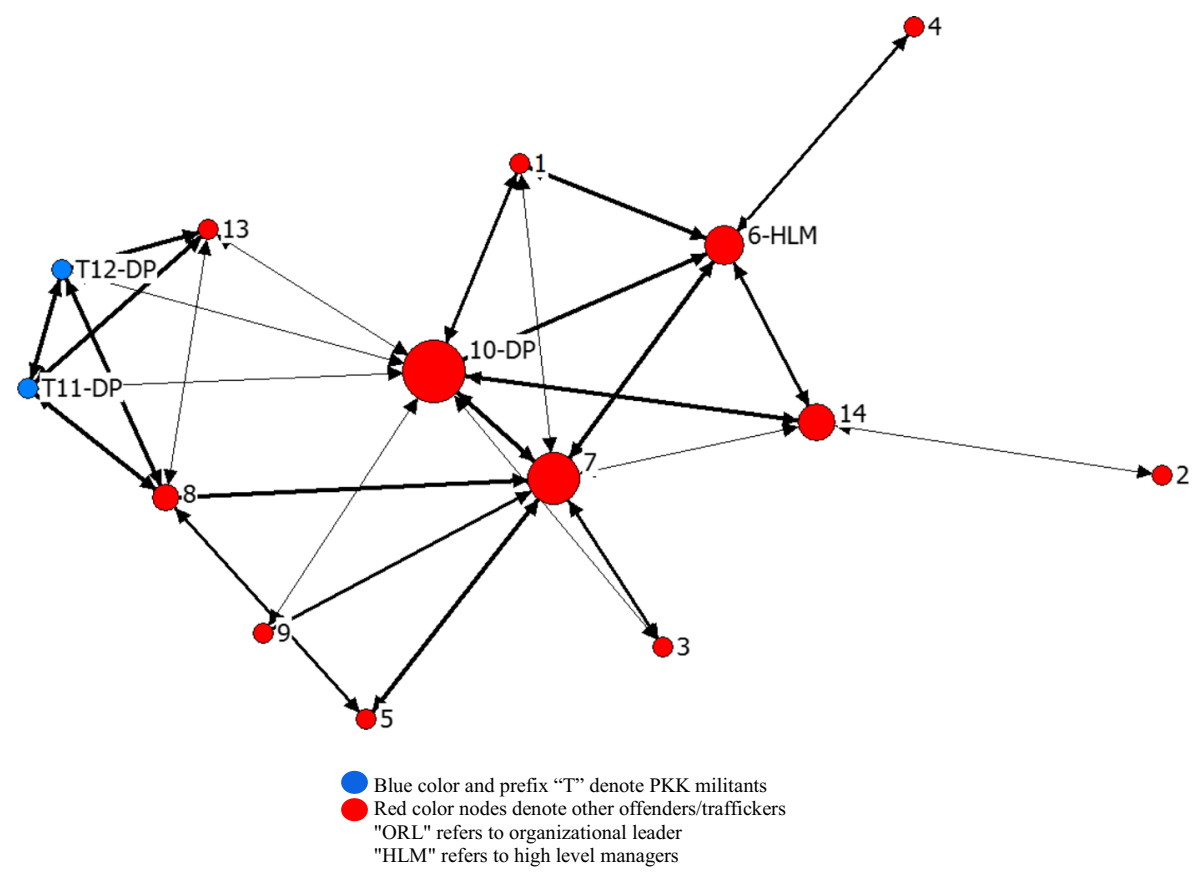

Fig. 3 Sociogram for network \#03

clique (nodes T2, 6, 11, 10). With a moderate core-peripheriness $(0.56)$, network \#04, as indicated in Fig. 4, has two clusters weakly tied to the relatively higher clustering coefficient (0.63) and transitive structure (22.64\%) with a short (average) path of 2.1, as depicted in Table 7. The level of clustering and path length indicate reliance on efficiency, but key players' positions, weak ties between two clusters, and high levels of kinship and peer structure reflect the network's effort to achieve security, as well. With the exception of four members, all of the other members were captured and arrested (including five of the terrorists).

Network\#05 This case represents an all Turkish, 10-member network, five of whom are terrorists, trafficking hashish and marijuana. As in most other sample cases, terrorist nexus predominantly controls the flow of information and resources. As shown in Fig. 5, T3-HLM indicates the most direct ties (7) and the shortest paths (16.66) to all others (Table 5). He has strong ties with all other terrorists (T4, T5, T6, and T10), as shown in Fig. 5. Terrorist members reflect strong kinship structures, in that T6 and T4 and 7 are brothers. As depicted in the sociogram (Fig. 5), the leader (9-ORL) is less prominent in terms of degree centrality and is positioned on the periphery, with only two direct and strong ties (bolder line) to two terrorists (T3-HLM and T-6).

The network has higher core-peripheriness (0.66) around the T3-HLM (constraint of 0.397 ) as well as higher connectedness with transitivity of $25.64 \%$, short geodesic distance of 1.76 , and density of 0.38 (Table 7). Given relatively higher centralization, connectedness, and short paths with higher density, network \#05 seems to rely more on efficiency than security. All members except T5 were captured and arrested. 


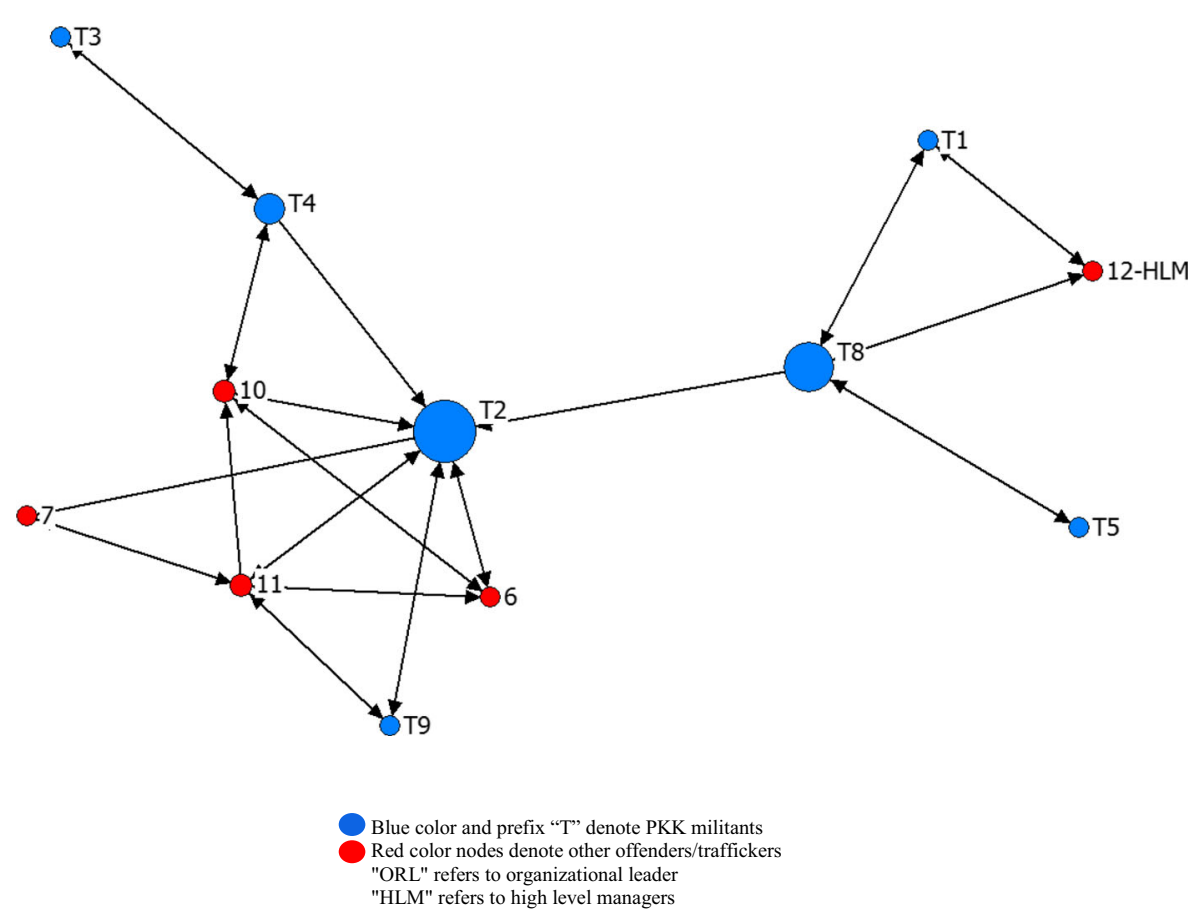

Fig. 4 Sociogram for network \#04

\section{Discussion}

This section discusses and relates the findings to prior research to address each of the hypothesis related to security-efficiency trade-off.

Table 4 Network \#04 - Actor-by-actor power and centrality scores

\begin{tabular}{llllll}
\hline Node & Degree & Between. & Close. & Constraint & Coreness \\
\hline T1 & 2 & 0 & 29 & 1.125 & 0.052 \\
T2 & 6 & 34 & 16 & 0.457 & 0.582 \\
T3 & 1 & 0 & 33 & 1 & 0.052 \\
T4 & 3 & 10 & 23 & 0.611 & 0.226 \\
T5 & 1 & 0 & 30 & 1 & 0.04 \\
6 & 3 & 0 & 23 & 0.882 & 0.37 \\
7 & 1 & 0 & 31 & 1 & 0.119 \\
T8 & 4 & 26 & 20 & 0.469 & 0.172 \\
T9 & 2 & 0 & 24 & 1.125 & 0.271 \\
10 & 4 & 3 & 21 & 0.732 & 0.297 \\
11 & 5 & 11 & 21 & 0.492 & 0.509 \\
$12-H L M$ & 2 & 0 & 29 & 1.125 & 0.052 \\
\hline
\end{tabular}




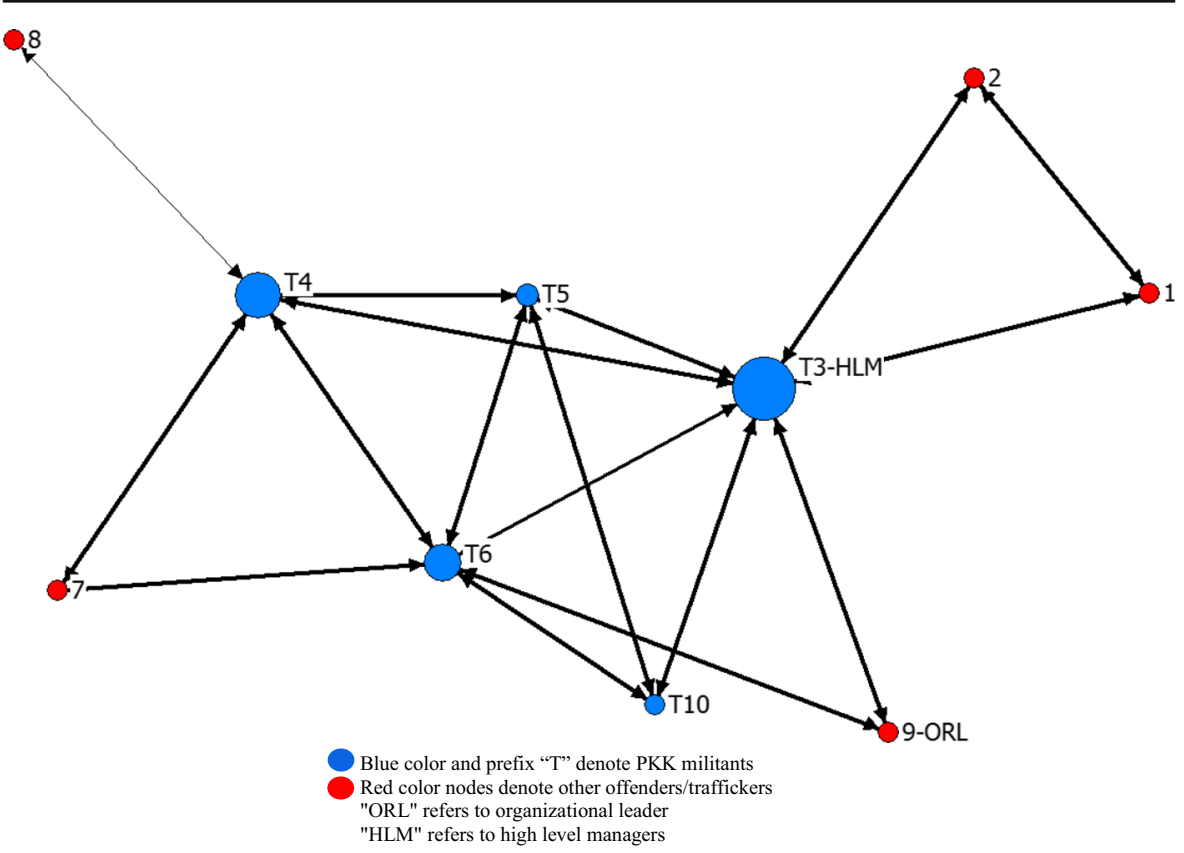

Fig. 5 Sociogram for network \#05

\section{The nature of the nexus, positions of PKK militants}

- Hypothesis: "key players are positioned more in the periphery than the core (for concealment and security)"

In light of the aforementioned findings for each individual sample networks, the PKK (terrorist nexus) dominates the control and coordination of the networks given terrorist members' powerful/central positions, e.g., gateway, central hub and key roles, leader,

Table 5 Network \#05 - Actor-by-actor power and centrality scores

\begin{tabular}{llllll}
\hline Node & Degree & Between. & Close. & Constraint & Coreness \\
\hline 1 & 2 & 0 & 18 & 1.125 & 0.13 \\
2 & 2 & 0 & 18 & 1.125 & 0.13 \\
T3-HLM & 7 & 16.667 & 11 & 0.397 & 0.537 \\
T4 & 5 & 10 & 13 & 0.491 & 0.363 \\
T5 & 4 & 0.667 & 14 & 0.74 & 0.377 \\
T6 & 6 & 6.667 & 12 & 0.487 & 0.492 \\
7 & 2 & 0 & 18 & 1.125 & 0.169 \\
8 & 1 & 0 & 21 & 1 & 0.07 \\
$9-$ ORL & 2 & 0 & 17 & 1.125 & 0.206 \\
T10 & 3 & 0 & 16 & 0.926 & 0.295 \\
\hline
\end{tabular}


manager, and drug provider. Contrary to terrorist activity, which is handled with the utmost secrecy and concealment by nature, terrorists who engaged in drug trafficking activities to finance their terrorist acts do not seem to rely more on security given their roles and positions.

Hence, this result does not support the aforementioned hypotheses and opposes certain assertions made on the positions of key players in dark networks. For instance, Baker and Faulkner [34: 856] argue that criminal groups weighed security over efficiency by having certain key players (top executives) positioned on the periphery structures, i.e., with less direct ties and less visibility, to refrain from security vulnerabilities. Concurring this, Duxbury and Haynie [72: 239] underline that key players (high profile members/distributors) opt to insulate themselves from the core activity and incidences of network activity by connecting only a few actors. In line with this, Morselli [73: 390] argue that key players (top executives) are positioned in periphery structures, i.e., with less direct ties and more betweenness, to mitigate security vulnerabilities by protecting key actors and limiting the risk of disruption by elimination of key players. Morselli et al. [25: 152] suggest that the image of the kingpin (hierarchical ruler) has changed to be a more flexible entrepreneur. Yet, Crossley et al. [31:2] argue that leaders in dark networks may tend to avoid a high position for secrecy reasons but their desire to control the network would lead to establishing a central intermediary position (high betweenness), which is partly supported by the findings of this research.

However, as Sparrow [21] points out, leaders might establish a position in which they exercise authority without having a central position in a network, and all central positions in a network do not always reveal the leadership positions as partially supported by certain cases (e.g., \#05 and \#04) in this analysis.

\section{Cohesion and connectedness}

- Hypothesis: "sample narco-terrorist networks, as having terrorist nexus, are sparse"

In terms of cohesion, density scores for the sample narco-terrorist networks range from 0.13 to 0.38 , as plotted in Table 7 . With regard to density, as previously mentioned, network density scores tend to decrease as the size of a network increases. In support of this, while the largest network (21 members), network \#01, has a density of 0.20 , network \#05, with the lowest number of offenders (10 members), has a density of 0.38 . However, network \#02, with a larger size compared to networks \#03 and \#04, has the lowest density of 0.13 , as depicted in Table 7.

When compared to the covert networks analyzed in the literature (acknowledging the difference in nature of the activities), the sample networks analyzed in this study reflect both sparser and denser structures. For instance, Baker and Faulkner [34: 851] analyze conspiracy networks and find a density of 0.35 for a network with a size of 24 members and density of 0.32 for a network with 21 members, thus, indicating denser structures than their Turkish counterparts with a similar size, e.g., \#01 and \#02. However, these two sample networks are denser when compared to a drug network comprised of 38 members yielding 0.12 density, as reported by Natarajan [36]. Koschade [17: 570], in his analysis of the Jemaah Islamiyah terrorist organization's Bali bombing cell, finds that the attack cell has a density score of 0.43 . However, Bright 
et al. [51: 163] report that densities of criminal networks in illicit markets, including drug and price-fixing groups, range between 0.053 to 0.25 . Given these findings, most of the sample networks seem to have denser structures given their size and certain other cohesion and connectedness metrics. In the end, as Oliver et al. [47: 8] note, there is no accepted threshold value to deem a covert network's sparseness or denseness. So, given what Bright et al. [51] report, narco-terrorist nexus reflects more incidences of relations for effective communication and coordination-leaning on efficiency.

As supplementary metrics of cohesion and connectedness, sample narco-terrorist networks yield high clustering coefficients (between 0.63 and 0.78 ), except for network \#02 (0.17), which is more security driven with a star-like sparse structure indicating central hubs controlled by two terrorists. Also verified by the average geodesic path distance, transitivity and average nodal degree, network \#02 has the highest average path (2.94) among members to reach one another and the least transitivity $(2.632 \%)$ with incomplete edges. Lindelauf et al. [33] suggest that this structure is more optimal (in terms of security), in that covert networks are to be a more centralized hub (star-like) with shorter path lengths (sparse structure) between members when operating in a hostile environment in their initial stage of operation. However, despite the low incidence and less direct ties among members, such a structure is found to cause security vulnerabilities of complete termination when these central hubs are compromised [32]. Offenders in other cases (e.g., \#01, \#03, \#04, \#05), however, are closer and more connected to each other without having to go over strict gateways/hubs to reach one another compared to network \#02. Compared to the September 11 hijacker cell with an average path length of 4.75 for 19 hijackers [18], the sample networks indicate shorter paths between offenders in general.

Conversely, Milward and Raab [20] argue that networks with shared values and preexisting ties tend to have higher cohesion and connectedness (e.g., density) in networks, while some claimed that specific attributes of members affect density: for instance, more skilled members lead to less density structures ([46]: 806). In light of this, higher densities of sample networks can be explained by these networks' striving to balance their structural security vulnerabilities through strong, pre-existing, trust ties, both kinship and friendship (see Table 8 for pre-existing ties).

\section{Centrality}

- Hypothesis: "sample narco-terrorist networks, as having terrorist nexus, are decentralized"

Table 6 plots normalized (0-100\%) scores of networks' average centrality and group centralization scores. The overall results indicate relatively lower and higher results for different centrality and centralization metrics, having different structural implications and thus results do not particularly support the hypothesis. For instance, while certain cases (e.g., network \#02) indicate a smaller number of direct ties (degree of 13.23\%) and lower average geodesics (path distance) between offenders (closeness centrality of $35.55 \%$ ), others (\#03 and \#05) indicate the highest scores in the same accounts (degree of 29.67 and 37.77 and closeness of 51.96 and 55.03, respectively), as depicted in Table 6. Considering conspiracy groups analyzed by Baker and Faulkner [34], their results yield both higher and lower centralization figures, e.g., conspiracy groups have 


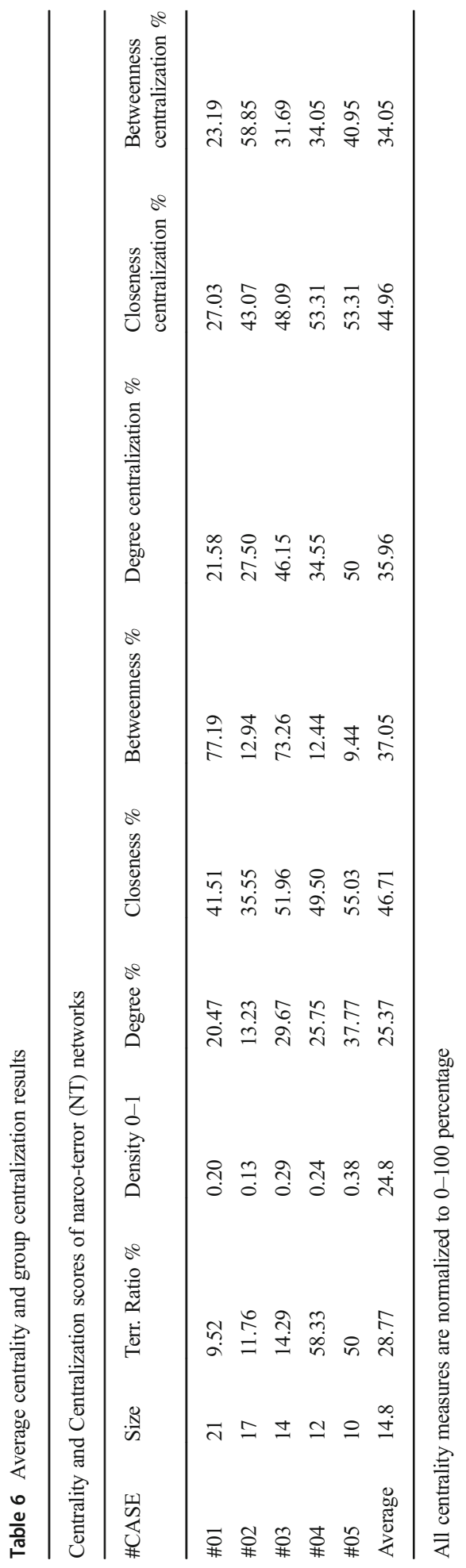


centralization scores for degree 41.7, 36.1, and 51.4; betweenness 21.3, 17.6, and 24.2; and closeness $39.0,37.4$, and 60.8 .

When brokerage is considered, networks \#01 and \#03 have a higher number of actors in intermediate positions to coordinate and control relationships (betweenness 77.19 and $73.26 \%$, respectively). However, when considering their reliance on a certain actor's pivotal role, group betweenness centralization scores indicate that network \#02, with a star-like structure, has stricter reliance on central hubs and the offenders around it (the highest betweenness centralization is $58.85 \%$ ), however with unconnected edges. This means that two terrorists in these networks have high control and authority (kingpin role) over the flow of information and resources with less relational ties among members. While such a structure reflects more reliance on security [33], it indicates that the network is vulnerable to complete termination (structural hole) when compromised [32]. Contrary to this, such dependence (the flow of information and resources) to particular offenders is not the case for network \#01, particularly when separately considering each of the tight-knit clusters. With regard to centrality and centralization, the results in the literature are mixed. While Natarajan [52] and Klerks [53] find illicit groups to be decentralized to a certain degree for security concerns, Baker and Faulkner [34] find three conspiracy networks to be reasonably centralized $(60.8 \%)$ and claim the opposite.

Table 6 also plots the ratio (percentage) of terrorists. As far as the scale of the terrorist nexus in networks is concerned, there is no clear-cut pattern indicating a covariance between the terrorist ratio and density, average degree centrality, closeness, and betweenness centrality. However, there is an unclear tendency that a higher terrorist ratio indicates that offenders have more direct ties and are closer to each other in path distance, e.g., networks \#03, \#04, and \#05, as depicted in Table 6. Such a rough pattern also exists in connectedness metrics of clustering coefficient and average geodesic (path) distance. As depicted in Table 7, these networks (i.e., \#03, \#04, and \#05) reflect more clustering into dense subgroups as well as shorter average path distance.

\section{Coreness}

- Hypothesis: "the flow of information in sample networks has long path length and tend to be less clustered in tight-knit subgroups reflecting less coreness"

Results reveal that the sample networks are clustered in dense subgroups with short distances among members, which does not support the above hypothesis. This result, concurs the two main claims made by Morselli et al. [25]. First, they argue that while terrorist networks put more distance between members, criminal networks are marked by shorter distance reflecting dense clusters and cliques, as evident in the aforementioned cohesion and connectedness results. Second, despite having a terrorist nexus, criminal networks are found to be more efficiency driven because the nature of their objective (material incentive) dominates the structure of dark networks. By the same token, Morselli et al. [25: 148] also argue that criminal networks, particularly illicit drug trafficking groups, are structurally built outward from one core to ensure more efficient communication and coordination, while terrorist networks lack this core due to an increased focus on security. Despite that the data used in this study only has static representation of the structure and does not give temporal changes, the results of this 
Table 7 Cohesion and connectedness scores

\begin{tabular}{lclllllll}
\hline \#CASE & Size & $\begin{array}{l}\text { Terr } \\
\text { Ratio } \\
\%\end{array}$ & $\begin{array}{l}\text { Density } \\
0-1\end{array}$ & $\begin{array}{l}\text { Overall } \\
\text { clustering } \\
\text { coefficient }\end{array}$ & $\begin{array}{l}\text { Average } \\
\text { Geo. } \\
\text { distance } \\
\text { (Path } \\
\text { Length) }\end{array}$ & $\begin{array}{l}\text { Network } \\
\text { transitivity } \% \\
\text { (Adjacency) }\end{array}$ & $\begin{array}{l}\text { Average } \\
\text { nodal } \\
\text { Degree }\end{array}$ & $\begin{array}{l}\text { Core- } \\
\text { Peripheriness } \\
\text { (Correlation) }\end{array}$ \\
\hline \#01 & 21 & 9.52 & 0.20 & 0.64 & 2.47 & 22.61 & & \\
$\# 02$ & 17 & 11.76 & 0.13 & 0.17 & 2.94 & 2.632 & 2.09 & 0.4 \\
$\# 03$ & 14 & 14.29 & 0.29 & 0.71 & 1.88 & 21.25 & 3.85 & 0.56 \\
$\# 04$ & 12 & 58.33 & 0.24 & 0.63 & 2.1 & 22.64 & 2.66 & 0.54 \\
$\# 05$ & 10 & 50 & 0.38 & 0.78 & 1.76 & 25.64 & 3.40 & 0.66 \\
Average & 14.8 & 28.8 & 0.25 & 0.59 & 2.23 & 22.64 & 3.22 & 0.46 \\
\hline
\end{tabular}

study support [25] findings in terms of reflecting coreness given the sociograms and coreness scores (four out of five samples have coreness above 0.50), as depicted in Table 7.

\section{Trust ties}

- Hypothesis: "sample narco-terrorist networks have strong trust ties (to maintain group solidarity against infiltration and defection)."

The results revealed that kinship and peer structures, known as trust ties, are important characteristics of the sample networks (Table 8), supporting the above hypothesis. Importance of trust ties in criminal networks is supported by many in the literature (e.g., $[20,31,43-45,47])$. Trust ties reduce the vulnerability and increase the resilience of covert networks ([47]: 4) through policing of one another to support in-group solidarity [20] and facilitating self-sacrifice ([31]: 3). Therefore, as [43, 45] argue, pre-existing contacts are important for the growth of networks over their members, which make social ties and trust-based relations important for the social structures of dark networks.

The overall structural characteristics in the security-efficiency tradeoff As a result, despite the fact that the ratio of terrorists in sample narco-terror networks ranges from $9.52 \%$ to $58.33 \%$, as depicted in Table 7 , the terrorist nexus dominates the control and

Table 8 Pre-existing ties and density

\begin{tabular}{lllllll}
\hline Case \# & Size & \#Kinship & \%Kinship & \#Peer & \%Peer & Density \\
\hline$\# 01$ & 21 & 7 & 33.3 & 0 & 0 & 0.20 \\
$\# 02$ & 17 & 6 & 35.29 & 14 & 82.35 & 0.13 \\
$\# 03$ & 14 & 3 & 21.42 & 11 & 78.6 & 0.29 \\
$\# 04$ & 12 & 4 & 33.3 & 11 & 91.6 & 0.24 \\
$\# 05$ & 10 & 3 & 30 & 9 & 90 & 0.38 \\
Average & 15.5 & 6.5 & 33.3 & 8.5 & 56.2 & 0.24 \\
\hline
\end{tabular}


coordination of the networks, given the structural positions of PKK militants in sample networks. So, one can suggest that, within most of the sample narco-terrorist networks in this study, the terrorist nexus constitutes the core part in which terrorists have key roles (at the strategic level) and are placed in pivotal positions.

More specifically, PKK members have high power and centrality either in controlling hubs or bridging separate subgroups. This is most evident in their centrality in different respects, such as degree centrality, closeness, and betweenness. In certain cases, they act as a gateway with a high brokerage role (e.g., \#04, \#01); in others they control central hubs (e.g., \#02). They are positioned in the center of a core (e.g., \#05), while in one of the cases they are positioned on the periphery (i.e., \#03), having a strategic level role, i.e., drug provider, supplying the drug to be trafficked. Results indicate that most hypotheses are not supported in the bulk of the five sample drug networks affiliated with the PKK. This is important to note that the terrorist nexus (PKK members) occupy critical positions (central hub and high brokerage role) despite their ideologically driven motives that would make them-individually-more security-oriented (at the peripheries with less incidence).

Second, the overall results yield that structural characteristics of sample narco-terrorist networks - at the network level_-are more efficiency driven given their density and centrality scores, as discussed earlier. The overall results indicate that the sample networks tend to reflect small and relatively denser clusters in their cores and peripheries and short distance among members, reflecting more reliance on efficiency in communicationdespite the terrorist nexus in them. Another important point to note is that, as having key and dominating roles (organizational leader, high level managers), the terrorist nexus (PKK militants) are expected to make the entire network more security driven (e.g., sparse, decentralized) as argued by Crossley et al. [31]. While this study does not measure the temporal secrecy level, terror activity is, by nature, considered to be more underground given the level of the risk, magnitude of the destructiveness/cost, and ideological motivation $[43,44]$. Thus, narco-terrorist networks, having a terrorist nexus, are expected to be less dense and less centralized. However, given the aforementioned density and centrality scores for certain criminal and terrorist networks analyzed in the literature as well as other connectedness metrics, the sample networks analyzed here seem to be denser (more incidence) and moderately centralized. This means that PKK affiliated narco-terror networks in Turkey are efficiency driven despite the dominance of ideologically-driven members - namely PKK militants in key roles and positions - running these networks. This supports the Morselli et al. [25] in that the nature of the activity (profit maximization, material gain) determines covert networks' prioritization between security and efficiency.

\section{Conclusion}

This study analyzed the structural characteristics of five sample PKK related narcoterror networks to decipher the terrorist nexus in criminal networks in particular and the overall network characteristics in general. Overall, the results revealed that PKK militants (coded as terrorists) dominate PKK affiliated narco-terror networks in Turkey. In that, PKK militants exert high authority and control by keeping structurally critical positions in these networks. For instance, PKK militants serve as a central hub in 
certain cases, while they act as a gateway with high intermediary and brokerage role controlling the flow of information and resources in others. Moreover, PKK militants have key roles, e.g., as organizational leaders, high-level managers, and drug suppliers in certain cases. So, PKK militants take powerful and central positions either in controlling hubs or bridging separate subgroups or in transporting the drug to be trafficked. In light of this, the 'terrorist nexus' is found to constitute the core parts of most sample networks, in which terrorists have key roles (at the strategic level) and are placed in pivotal positions. In short, terrorists were found to dominate the control and coordination of communication and the flow of resources.

In terms of general structural characteristics, most sample (narco-terrorist) networks tend to be clustered (clustering coefficient, transitivity) into dense subgroups attached to networks' cores (coreness) reflecting relatively denser and centralized structures (density and centrality). In that, offenders are closer to one another (path distance) with more incidence (nodal degree). Yet, the results indicated no clear-cut pattern between the terrorist ratio and network structures. However, there is a rough correlation: the larger the terrorist nexus, the closer the offenders are to one another and with more direct ties.

On the other hand, as known, social, political, economic, geographical, and cultural characteristics of a country or a region have important influences on drug trafficking and related crimes. In this regard, PKK related drug networks reflect important kinship structures (pre-existing trust ties). This is largely due - in addition to demographic and socio-cultural characteristics of Turkey's Southeast and East regions - that these narcoterror networks seem to balance the density and centralization with increased trust levels through group solidarity, self-sacrifice and shared values to maintain secrecy and security and to keep these networks more resilient against defection and infiltration. From a social network perspective, relational ties between offenders can exert a robust influence on the collective behavior of the group as a whole. Particularly in areas where family ties and bonds are culturally strong as is the case of the Columbian drug cartels and insurgent groups (e.g., FARC), for the PKK, Kurdish ethnographical ties among Turkey's Southeastern region are marked by feudal social structures with strong familial and blood ties [74] as evident in the findings of this research.

In the aforementioned regards, social bonds do matter in how these PKK affiliated narco-terror networks are structured, operate, and grow. Social bonds in narco-terror activities in the Turkish context. This is due by large to historical ties among populations in between regions that lie in Balkan Route. Kurds, for instance, living in Turkey, Iran, Iraq and Syria share similar linguistic, cultural, and familial characteristics and this particularly promotes communication and ties across the borders. In a similar vein, Turks living in Istanbul, Bursa, Edirne have kinship ties with Turkish people inhabiting in Greece, Bulgaria, Macedonia, Kosovo, Bosnia, and Romania [58]. Yet, there exist a large Kurdish population living in European countries, constituting a large diaspora across the Europe [28]. The use of social bonds as pre-existing ties, therein constituting trust ties, seems to contribute to effectiveness and security both internally and externally. This brings important policy implications that supports Krebs' [18] study. In that, social bonds and ties, namely, friendship and relatives for the PKK related drug networks may provide an important tool for law enforcement agencies during their investigations to have more successful results, police and other law enforcement agencies may focus on these ties. 
Finally, despite the fact that terrorists dominate and control the sample narco-terror networks, they seem to rely more on efficiency than security given the nature of communication (flow of information and resources). Given this, the results support and oppose two claims made by Morselli et al. [25] First, they argue that terrorist and criminal networks are methodically different due to the nature of their activity, in which criminal networks are more efficiency-driven, and thus, they have shorter time-to-task. Meanwhile, it is the opposite for terrorist groups. Given the roles and positions taken by PKK militants, this claim is not supported. Despite that PKK militants are ideologically driven individuals who are expected to be more security driven in terms of network level and individual level characteristics, they are found to be prioritizing efficiency over security. In that, PKK militants are attached to networks' core in most cases they occupy the central (hub) or critical (gateway) position with more incidence (degree) as well as with more critical ties brokering different subsets, cliques, or core(s). So, PKK militants are not, in most cases, positioned in the peripheries for security concerns but are in powerful positions exerting control and authority at the individual level. At the network level, analyses indicated similar results in terms of security-efficiency tradeoff. Sample narco-terror networks seem to be denser (more incidence) and moderately centralized when compared with density and centrality scores for certain criminal and terrorist networks analyzed in the literature. So, PKK affiliated narco-terror networks in Turkey prioritize efficiency over security although PKK militants, as ideologicallydriven members, dominate the key roles and positions in these networks.

However, Morselli et al. [25] also argue that the nature of the activity dominates the structural characteristics of dark networks in their prioritization of security and efficiency. From this perspective, the results strongly support this claim, in which the nature of the activity, i.e., illicit drug trafficking and the motive, i.e., material gain, profit maximization (shorter time to task), dominates how offenders behave and how these networks are structured. Given that ideologically driven PKK militants dominating key roles and critical positions in sample narco-terror networks' structures, one would expect these networks to be more security driven. However, as Morselli et al. [25] suggest, the overall motive - material gain — overwhelms PKK militants' ideologically driven nature when operating in criminal activity. So, one can, then, suggest that the nature of the activity (e.g., aim, objective, motive) rather than the essential motives of dominant offenders (PKK militants in this case) is more influential on how the sample narco-terror networks are structured in prioritizing between security and efficiency in Turkish context. In that time to task is shorter in illicit drug trafficking activity and the main aim is to realize the benefit asap and the motive is material gain and this nature makes sample narco-terror networks are more efficiency driven-as evident in network topographies.

As a result, the PKK militants, as the ideologically driven terrorist nexus, dominates the control and coordination of narco-terrorist networks in terms of position and role in the Turkish context. However, despite the nature of terrorist activity (more underground) with its ideological motives that would make these networks more security driven, narco-terror networks in Turkish context focus more on efficiency. This is so at both, individual (i.e., PKK militants' positions and roles) and network level (i.e., density, centralization, coreness, average path length). So, the terrorist nexus comprised of PKK militants does not seem to make these networks more securitydriven. 
For the future research, it is recommended that temporal changes (given that the data analyzed here is secondary and only reflect static representation) from the beginning to disruption of the narco-terror networks are to be analyzed to identify the emergence and dominance of terrorist nexus in criminal networks, particularly illicit drug groups, in order to infer more on necessary security measures and security implications for law enforcement units.

\section{References}

1. Howard, R. D., Traughber, C. M. (2008). New silk road of terrorism and organized crime: The key to countering the terror-crime Nexus. in Jeffrey H. Norwitz, ed., Armed Groups: Studies in National Security, Counterterrorism, and Counterinsurgency (Government Printing Office) 371-387.

2. Hutchinson, S., \& O'malley, P. (2007). A crime-terror Nexus? Thinking on some of the links between terrorism and criminality 1. Studies in Conflict Terrorism, 30(12), 1095-1107.

3. Makarenko, T. (2004). The crime-terror continuum: Tracing the interplay between transnational organised crime and terrorism. Global Crime, 6(1), 129-145.

4. Makarenko, T., \& Mesquita, M. (2014). Categorising the crime-terror nexus in the European Union. Global Crime, 15(3-4), 259-274.

5. Björnehed, E. (2004). Narco-terrorism: The merger of the war on drugs and the war on terror. Global Crime 6(3-4), 305-324.

6. Lee, R. (2008). The Triborder-terrorism nexus. Global Crime, 9(4), 332-347.

7. Oehme, C. G., III. (2008). Terrorists, insurgents, and criminals - Growing Nexus? Studies in Conflict \& Terrorism, 31(1), 80-93.

8. Shelley, L., \& Picarelli, J. T. (2005). Methods and motives: Exploring links between transnational organized crime and international terrorism. Trends in Organized Crime, 9(2), 52-63.

9. Wang, P. (2010). The crime-terror nexus: Transformation, alliance, convergence. Asian Social Science, 6(6), 11-17.

10. Dishman, C. (2001). Terrorism, crime, and transformation. Studies in Conflict and Terrorism, 24(1), 43-58.

11. Freeman, M. (2011). The sources of terrorist financing: Theory and typology. Studies in Conflict \& Terrorism, 34(6), 461-475.

12. Meierrieks, D., \& Schneider, F. (2016). The short-and long-run relationship between the illicit drug business and terrorism. Applied Economics Letters, 23(18), 1274-1277.

13. Piazza, J. A. (2011). The illicit drug trade, counternarcotics strategies and terrorism. Public Choice, 149(3), 297-314.

14. Clarke, R., \& Lee, S. (2008). The PIRA, D-company, and the crime-terror nexus. Terrorism and Political Violence, 20(3), 376-395.

15. Shelley, L., \& Picarelli, J. T. (2002). Methods not motives: Implications of the convergence of international organized crime and terrorism. Police Practice and Research, 3(4), 305-318.

16. Belli, R., Freilich, J. D., Chermak, S. M., \& Boyd, K. A. (2015). Exploring the crime-terror nexus in the United States: A social network analysis of a Hezbollah network involved in trade diversion. Dynamics of Asymmetric Conflict, 8(3), 263-281.

17. Koschade, S. (2006). A social network analysis of Jemaah Islamiyah: The applications to counterterrorism and intelligence. Studies in Conflict \& Terrorism, 29(6), 559-575.

18. Krebs, V. E. (2002). Mapping networks of terrorist cells. Connections, 24(3), 43-52.

19. McGloin, J. M., \& Kirk, D. S. (2010). An overview of social network analysis. Journal of Criminal Justice Education, 21(2), 169-181.

20. Milward, H. B., \& Raab, J. (2006). Dark networks as organizational problems: Elements of a theory. International Public Management Journal, 9(3), 333-349.

21. Sparrow, M. K. (1991). The application of network analysis to criminal intelligence: An assessment of the prospects. Social Networks, 13(3), 251-274.

22. Van der Hulst, R. C. (2009). Introduction to social network analysis (SNA) as an investigative tool. Trends in Organized Crime, 12(2), 101-121.

23. Ballina, S. (2011). The crime-terror continuum revisited: A model for the study of hybrid criminal organisations. Journal of Policing, Intelligence and Counter Terrorism 6(2), 121-136. 
24. Asal, V., Milward, H. B., \& Schoon, E. W. (2015). When terrorists go bad: Analyzing terrorist organizations' involvement in drug smuggling. International Studies Quarterly, 59(1), 112-123.

25. Morselli, C., Giguère, C., \& Petit, K. (2007). The efficiency/security trade-off in criminal networks. Social Networks, 29(1), 143-153.

26. Ünal, M. C. (2016). Terrorism versus insurgency: A conceptual analysis. Crime Law and Social Change, $66(1), 21-57$.

27. Roth, M. P., \& Sever, M. (2007). The Kurdish workers party (PKK) as criminal syndicate: Funding terrorism through organized crime, a case study. Studies in Conflict \& Terrorism, 30(10), 901-920.

28. Unal, M. C. (2012). Counterterrorism in Turkey: Policy choices and policy effects toward the Kurdistan workers' party (PKK). New York: Routledge.

29. Everton, S. F., \& Cunningham, D. (2015). Dark network resilience in a hostile environment: Optimizing centralization and density. Criminology, Criminal Justice Law \& Society, 16, 1.

30. Zech, S. T., \& Gabbay, M. (2016). Social network analysis in the study of terrorism and insurgency: From organization to politics. International Studies Review, 18(2), 214-243.

31. Crossley, N., Edwards, G., Harries, E., \& Stevenson, R. (2012). Covert social movement networks and the secrecy-efficiency trade off: The case of the UK suffragettes (1906-1914). Social Networks, 34(4), 634-644.

32. Enders, W., \& Su, X. (2007). Rational terrorists and optimal network structure. Journal of Conflict Resolution, 51(1), 33-57.

33. Lindelauf, R., Borm, P., \& Hamers, H. (2009). The influence of secrecy on the communication structure of covert networks. Social Networks, 31(2), 126-137.

34. Baker, W. E., \& Faulkner, R. R. (1993). The social organization of conspiracy: Illegal networks in the heavy electrical equipment industry. American Sociological Review, 58, 837-860.

35. Jordan, J., Mañas, F. M., \& Horsburgh, N. (2008). Strengths and weaknesses of grassroot jihadist networks: The Madrid bombings. Studies in Conflict \& Terrorism, 31(1), 17-39.

36. Natarajan, M. (2006). Understanding the structure of a large heroin distribution network: A quantitative analysis of qualitative data. Journal of Quantitative Criminology, 22(2), 171-192.

37. Schmid, A. P. (2005) Links between terrorism and drug trafficking: A case of 'narcoterrorism'?. International Summit on Democracy, Terrorism and Security, January 27.

38. Vargas, G. A. (2011). Drugs, hearts and minds: Irregular war and the coca economy in south bolivar, Colombia (1996-2004). Civil Wars, 13(01), 21-39.

39. Teirilä, O. T. (2014). The challenges to cooperation posed by the nexus of terrorism and organized crime: Comparing the situations between the Andean and the Sahel regions. Studies in Conflict \& Terrorism, $37(1), 18-40$.

40. Raab, J., \& Milward, H. B. (2003). Dark networks as problems. Journal of Public Administration Research and Theory, 13(4), 371-439.

41. Levitt, S. D., \& Venkatesh, S. A. (2000). An economic analysis of a drug-selling gang's finances. The Quarterly Journal of Economics, 115(3), 755-789.

42. Bobic, M. (2014). "transnational organised crime and terrorism: Nexus needing a human security framework." Global Crime15, no. 3-4: 241-258.

43. Sageman, M. (2008). A strategy for fighting international Islamist terrorists. The Annals of the American Academy of Political and Social Science, 618(1), 223-231.

44. Mayntz, R. (2004) Organizational forms of terrorism: hierarchy, network, or a type sui generis? No. 04/ 4. Discussion Paper, 8. 14.

45. Erickson, B. H. (1981). Secret societies and social structure. Social Forces, 60(1), 188-210.

46. Helfstein, S., \& Wright, D. (2011). Covert or convenient? Evolution of terror attack networks. Journal of Conflict Resolution, 55(5), 785-813.

47. Oliver, K., Crossley, N., Edwards, G., Koskinen J., \& Everett, M. (2014). Covert networks: Structures, processes and types. Unpublished manuscript, University of Manchester, Manchester, UK, p. 4-13.

48. Rodriguez, J. (2009). Weakness and strengths of terrorist networks: The Madrid March 11 Attacks. In Annual Meeting of the American Sociological Association. Available at http://www.allacademic. com/meta/p243052 index. html. Accessed 17 Aug 2018.

49. Watts, D. C. (1999). Networks, dynamics, and the small-world phenomenon. American Journal of Sociology, 105(2), 493-527.

50. Granovetter, M. S. (1973). The strength of weak ties. American Journal of Sociology, 78(6), 1360-1380.

51. Bright, D. A., Hughes, C. E., \& Chalmers, J. (2012). Illuminating dark networks: A social network analysis of an Australian drug trafficking syndicate. Crime, Law and Social Change, 57(2), 151-176.

52. Natarajan, M. (2000). Understanding the structure of a drug trafficking organization: A conversational analysis. Crime Prevention Studies, 11, 273-298. 
53. Klerks, P. (2001). The network paradigm applied to criminal organizations: Theoretical nitpicking or a relevant doctrine for investigators? Recent developments in the Netherlands. Connections, 24(3), 53-65.

54. Van Solinge, T. B. (1998). Drug use and drug trafficking in Europe. Tijdshrift voor Economische a Sociale Geografie., 89(1), 100-105.

55. UNDCP World Drug Report (2010). Available at https://www.unodc.org/documents/wdr/WDR_2010 /World_Drug_Report_2010_lo-res.pdf. Accessed 29 July 2019.

56. Curtis, G. E. \& T. Karacan. (2002). The nexus among terrorists, narcotics traffickers, weapons proliferators, and organized crime networks in Western Europe. In The Library of Congress, December.

57. United Nations Office on Drugs, and Crime. (2010). The globalization of crime [electronic resource]: A transnational organized crime threat assessment. United Nations Publications.

58. Turhal, T. (2015). Organizational structure of PKK and non-PKK-linked Turkish drug trafficking organizations: The influence of social bonds. PhD diss., pp. 105-107.

59. Unal, M. C. (2014). Strategist or pragmatist: A challenging look at Ocalan's retrospective classification and definition of PKK's strategic periods between 1973 and 2012. Terrorism and Political Violence, $26(3), 419-448$.

60. Ünal, M. C. (2016). Is it ripe yet? Resolving Turkey's 30 years of conflict with the PKK. Turkish Studies, $17(1), 91-125$.

61. Ünal, M. C. (2016). Counterin-surgency and military strategy: An analysis of the Turkish Army's COIN strategies/doctrines. Military Operations Research, 21(1), 55-88.

62. Gürcan, M. \& Ünal, M. C. (2018). Reaching a balance of resolve: The enduring conflict between Turkey and the PKK. In Deterring Terrorism (pp. 193-230). Routledge.

63. Radu, M. (2018). "The rise and fall of the PKK." in Dangerous Neighborhood, pp. 143-164. Routledge.

64. Picarelli, J. T. (2006). The turbulent nexus of transnational organised crime and terrorism: A theory of malevolent international relations. Global Crime, 7(1), 1-24.

65. Schoon, E. W. (2017). Building legitimacy: Interactional dynamics and the popular evaluation of the Kurdistan workers' party (PKK) in Turkey. Small Wars \& Insurgencies, 28(4-5), 734-754.

66. Wasserman, S., \& Faust, K. (1994). Social network analysis: Methods and applications (Vol. 8). UK: Cambridge university press.

67. Freeman, L. C. (1996). Some antecedents of social network analysis. Connections, 19(1), 39-42.

68. Hanneman, R. A., Riddle, M. (2005). "introduction to social network methods.", 81-93.

69. Burcher, M., \& Whelan, C. (2015). Social network analysis and small group 'dark'networks: An analysis of the London bombers and the problem of 'fuzzy'boundaries. Global crime, 16(2), 104-122.

70. Everton, S. S. (2008). Tracking, destabilizing and disrupting dark networks with social networks analysis., p. 98-154.

71. Borgatti, S. P., \& Everett, M. G. (2000). Models of core/periphery structures. Social Networks, 21(4), 375-395.

72. Duxbury, S. W., \& Haynie, D. L. (2018). Building them up, breaking them down: Topology, vendor selection patterns, and a digital drug market's robustness to disruption. Social Networks, 52, 238-250.

73. Morselli, C. (2010). Assessing vulnerable and strategic positions in a criminal network. Journal of Contemporary Criminal Justice, 26(4), 382-392.

74. Ünal, M. C. \& Ünal, T. (2017) Recruitment or enlistment? Individual integration into the Turkish Hezbollah. Turkish studies, 19 no 3 pp 1-36.

Publisher's note Springer Nature remains neutral with regard to jurisdictional claims in published maps and institutional affiliations. 